\title{
Pathogen-Host Defense in the Evolution of Depression: Insights into Epidemiology, Genetics, Bioregional Differences and Female Preponderance
}

\author{
Charles L Raison ${ }^{*, 1,2,3}$ and Andrew H Miller ${ }^{4,5}$ \\ ${ }^{1}$ Department of Human Development and Family Studies, School of Human Ecology, University of Wisconsin-Madison, \\ Madison, WI, USA; ${ }^{2}$ Department of Psychiatry, School of Medicine and Public Health, University of Wisconsin-Madison, \\ Madison, WI, USA; ${ }^{3}$ School of Pharmacy, University of Wisconsin-Madison, Madison, WI, USA; ${ }^{4}$ Department of Psychiatry and \\ Behavioral Sciences, School of Medicine, Emory University, Atlanta, GA, USA; ${ }^{5}$ The Winship Cancer Institute, Emory \\ University, Atlanta, GA, USA
}

\begin{abstract}
Significant attention has been paid to the potential adaptive value of depression as it relates to interactions with people in the social world. However, in this review, we outline the rationale of why certain features of depression including its environmental and genetic risk factors, its association with the acute phase response and its age of onset and female preponderance appear to have evolved from human interactions with pathogens in the microbial world. Approaching the relationship between inflammation and depression from this evolutionary perspective yields a number of insights that may reveal important clues regarding the origin and epidemiology of the disorder as well as the persistence of its risk alleles in the modern human genome. Neuropsychopharmacology Reviews (20 17) 42, 5-27; doi: I 0. I 038/npp.2016.194; published online 12 October 2016
\end{abstract}

"...when diseases have been common in human populations for many generations and still have a substantial negative impact on fitness, they are likely to have infectious causes....These infectious causes may be causes in the proximate sense (e.g., Mycobacterium tuberculosis causes tuberculosis) or in an evolutionary sense (Plasmodium falciparum is an evolutionary cause of sickle cell anemia)....The only such compensating fitness benefit that has been documented for major human genetic diseases is resistance to infection." - (Cochran et al, 2000) Cochran, Ewald \& Cochra.

\section{INTRODUCTION}

Major depressive disorder (MDD) is about relationships. Or so one would think based on an extensive literature that seeks to explain how a condition with genetic underpinnings could be so widespread when it is so apparently inimical to the Darwinian mandates of survival and reproduction. This literature on adaptive theory bifurcates over whether

${ }^{*}$ Correspondence: Dr CL Raison, School of Human Ecology, University of Wisconsin-Madison, 1300 Linden Drive, Room 4174, Madison, WI 53706, USA, Tel: 678429 9870, E-mail: charles.raison@wisc.edu

Received 30 May 2016; revised 28 August 2016; accepted 8 September 2016; accepted article preview online 15 September 2016 depression is adaptive in and of itself or whether the genes that increase the risk of depression also promote other types of social behavior (ie, avoiding conflict with more powerful individuals) that promoted survival and reproduction sufficiently to have been retained in the human genome (Supplementary Table S1). Despite differences, however, these theories all share in common the notion that the adaptive value of MDD is to be found in its effects on our relationships with other people.

We agree that the adaptive value of MDD is to be found in our relationships, but not primarily in our relationships with other humans. Rather, in this review we argue that MDD, and the genes that subserve it, evolved to help us manage relationships with the wide range of pathogens with which humans co-evolved. Specifically, at least some of the genes that promote MDD evolved and have been retained in the human genome because-on average-they helped hominids avoid death from infection. Importantly, we are not suggesting that these genes promoted host defense against pathogens at the cost of inducing depression. Rather, the tendency of these genes to induce depression and other related behavioral changes including arousal, anxiety and alarm is integral to their anti-pathogen benefits, becauselike sickness from which it evolved-depression conferred protection from pathogens in the environments in which humans evolved. Said differently, depression may itself be an anti-pathogen defense strategy, one that is both activated by 
inflammation and, somewhat paradoxically, one that across evolutionary time may have made inflammatory activation less necessary, as we shall see in our discussion of sex differences in the prevalence of MDD. From this perspective, even environmental risk factors for depression, such as psychosocial stress, promote MDD primarily because across evolutionary time these adversities reliably served as warnings that an individual's risk for infectious morbidity/ mortality were heightened. Although this perspective may be most relevant to sub-types of depression associated with increased inflammation, we highlight in this review the possibility that other immune and/or behavioral responses relevant to pathogen-host defense may also be associated with MDD in ways that extend the role of microbial-human interactions in the evolution of depression beyond its now well-recognized associations with inflammation.

Consistent with earlier publications from our group (Raison and Miller, 2012, 2013; Miller and Raison, 2015), we refer to this constellation of ideas as the pathogen-host defense theory of depression, or PATHOS-D. This position overlaps, but has significant differences from a pathogen defense theory of depression first articulated by Kinney and Tanaka, (2009) (Anders et al, 2013). Table 1 situates PATHOS-D within other possible explanatory frameworks for understanding why MDD and alterations in immune function should be related. Supplementary Table S1 provides a comparison of different adaptive explanations for the persistence of MDD and its risk alleles in human populations. As with all theories, the value of PATHOS-D will eventually be determined by its ability to make novel predictions and to provide coherent and parsimonious explanations for a wider range of variables than are accounted for by competing hypotheses. Our aim in this review is to evaluate PATHOS-D by these criteria. To do this, we list a series of concepts consistent with PATHOS-D theory, in each case evaluating the evidence for and against the theory's explanatory and predictive potential. In addition, we explore the theory's possible explanations for sex differences in the prevalence of MDD. In all these areas, we are careful to note the degree of data in support of each idea, and which ideas are frankly speculative. Figure 1 provides a graphic representation of epidemiological, biological, and genetic domains relevant to MDD that are addressed by PATHOS-D.

\section{DEPRESSION IS ASSOCIATED WITH IMMUNE CHANGES AND THESE SAME CHANGES SHOULD BE CAPABLE OF INDUCING DEPRESSION}

Of all the predictions of PATHOS-D, this one is the best established. Indeed, it was the effort to provide an evolutionary perspective on the association between inflammation and depression that provided the initial impetus for the theory. Taken as a whole, studies suggest that MDD is associated with all the cardinal features of an inflammatory response including increased proinflammatory cytokines and their receptors and increased acute phase reactants, chemokines, and soluble adhesion molecules in peripheral blood (Lieb et al, 1983; Calabrese et al, 1986; Sluzewska et al, 1996; Song et al, 1998; Howren et al, 2009; Dowlati et al, 2010; Liu et al, 2012b; Valkanova et al, 2013; Black and Miller, 2015; Haapakoski et al, 2015; Eyre et al, 2016; Goldsmith et al, 2016b; van Dooren et al, 2016). Several studies provide evidence of increased inflammatory activity in the central nervous system of depressed individuals as well, as indexed by increased cerebrospinal fluid (CSF) concentrations of interleukin (IL)-1- $\beta$ and neural adhesion molecules, as well as by increased prefrontal cortex gene expression of IL-1- $\alpha$, IL-2, IL-3, IL-5, IL-8, IL-9, IL-10, IL-12A, IL-13, IL-15, IL-18, interferon (IFN) $-\gamma$, and lymphotoxin alpha (TNF superfamily member 1; Poltorak et al, 1996, Levine et al, 1999; Shelton et al, 2010). Perhaps suggesting a link between inflammation and symptom acuity, and/or reflecting the association between inflammation and heightened anxiety (a known suicide risk), a recent meta-analysis found that levels of IL-1- $\beta$ and IL-6 were significantly increased in blood and postmortem brain samples of patients with suicidality compared with both non-suicidal depressed patients and healthy control subjects (Black and Miller, 2015). Given their centrality in activating innate immune responses to pathogens, it is striking that

\section{TABLE 1 Possible Evolutionary Understandings of the Association Between Depression and Inflammation/Immune Activation}

No adaptive relationship exists between immune changes and depressive symptoms. Immune changes observed in major depressive disorder (MDD) may be beneficial or detrimental to pathogen-host defense and adaptive benefits of depression exist in non-pathogen/immune-related domains (multiple adaptive theories, eg, social navigation hypothesis)

Depressive symptoms extract a cost to survival and reproduction but this cost is offset by the direct anti-pathogen benefits of heightened inflammation/immune activation (antagonistic pleiotropy)

In individuals with reduced immune competence for any number of reasons, depressive symptoms serve pathogen-host defense by inducing social avoidance/energy conservation and behaviors that provide protection from becoming infected and/or energy for immune activity once infection has occurred (Kinney and Tanaka)

Genetic alleles that promote an inflammatory bias have undergone positive selection because in ancestral environments they provided direct pathogen defense and because they promoted the development of depressive symptoms in response to immune activation. Like sickness behavior, depression in response to immune activation aided in host defense both directly (ie, raised body temperature and energy conservation behaviors) and indirectly (social avoidance, energy conservation, and hypervigilance; Raison and Miller, pathogenhost defense theory of depression [PATHOS-D]) mechanisms) 


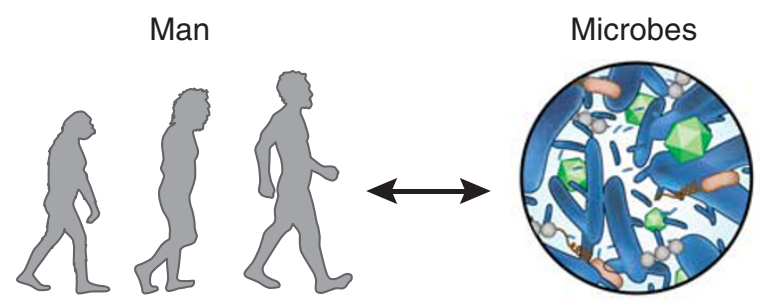

Ancestral environment

Evolutionary pressure

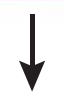

Epidemiology, phenomenology, genetics of immune-based depression
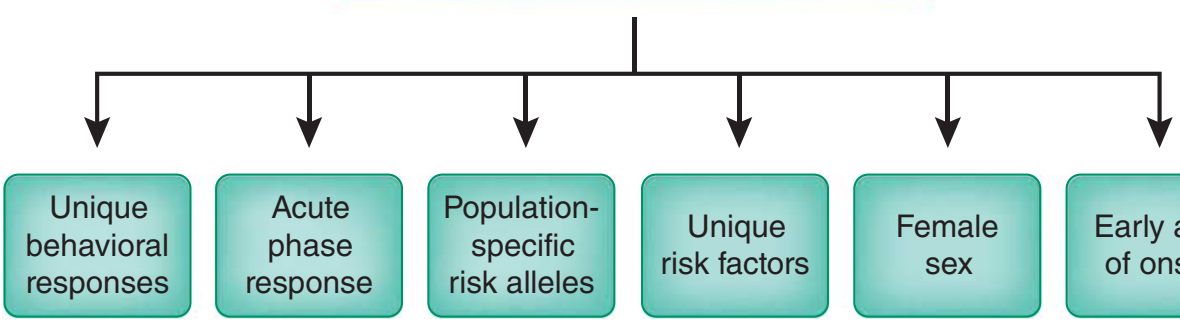

Early age of onset

Figure 1. Man meets microbes. In ancestral environments, heavy pathogen loads applied significant evolutionary pressure on human survival that ultimately entailed a host of adaptations that, according to the pathogen-host theory of depression, shaped interactions between the immune system (inflammation in particular) and the brain, leading to a unique set of behaviors. These behaviors, including anhedonia, fatigue, and psychomotor slowing as well as anxiety, arousal and alarm supported energy conservation for fighting infection and wound healing and hypervigilance to prevent future attack. In addition, these evolutionary forces instantiated a coupling of these behavioral responses with the acute phase response including not only increases in acute phase reactants such as c-reactive protein but also hypoferremia and zinc deficiency, as well as fever, which are better suited for interactions with pathogens than people. In addition, evolutionary pressures from human interactions with the microbial world can explain risk alleles that are specific to the pathogens to which given populations were exposed as well as epidemiologic features of depression such as female sex preponderance, an early age of onset, and occurrence in the postpartum period that supported reproductive success. Finally, the pathogen-host theory of depression is consistent with modern risk factors for depressive symptoms, including obesity, processed-food-based diets, sedentary lifestyle, and sleep deprivation, all of which serve to exacerbate the inflammatory bias that is the legacy of our evolutionary past.

Toll-like receptor (TLR) mRNA and protein have been reported to be elevated in both the periphery and CNS of individuals with MDD (Hung et al, 2014, 2015; Keri et al, 2014; van Dooren et al, 2016), with some evidence suggesting that successful pharmaco- or psychotherapy reduces peripheral TLR activity (Keri et al, 2014; Hung et al, 2015). Of these various findings, meta-analyses suggest that the best replicated associations between depression and inflammatory biomarkers are increases in circulating levels of c-reactive protein (CRP) and IL-6 (Howren et al, 2009; Dowlati et al, 2010; Liu et al, 2012b; Valkanova et al, 2013; Black and Miller, 2015; Haapakoski et al, 2015). Taken as a whole, the meta-analytic literature also supports an association with circulating levels of tumor necrosis factor (TNF) and IL-1- $\beta$, although with more variability. Because IL-1- $\beta$ features so prominently in both the inflammatory response and in animal studies of stress, and depression-like behavior, it is curious that meta-analyses split on whether it is elevated in the blood of patients with MDD (Dowlati et al, 2010; Black and Miller, 2015). One possible explanation that would be consistent with the animal literature is that IL-1- $\beta$ has a larger role in the CNS than the periphery in terms of depressogenesis. Consistent with this, some evidence suggests that IL-1- $\beta$ is elevated in the CSF of depressed individuals (Levine et al, 1999). Alternately, evidence linking IL-1- $\beta$ to MDD may not be robust because of limitations in assay methods in detecting levels of IL-1 in human studies. Although increases in inflammatory biomarkers in depressed patients compared with controls are modest when compared with acute infections or autoimmune conditions, recent animal data demonstrate that these types of low-level inflammatory stimulation are sufficient to induce depressive-like behavior and associated brain changes when such stimulation is chronic (Tarr et al, 2012a), such as appears to be the case in many individuals with MDD. 
Nonetheless, cross-sectional associations between MDD and inflammation do not establish that immune system activity is capable of producing depression, as would be predicted by PATHOS-D theory. It might well be that depression is associated with brain states that through their impact on neuroendocrine function secondarily increase inflammatory biomarkers that themselves have no impact on the disorder. However, a wealth of data demonstrate that although it is true that mental states can increase inflammation, it is equally true that activation of the body's inflammatory response system can induce depression, as well as many of the CNS and neuroendocrine changes that have been repeatedly associated with MDD. This has been shown in studies examining the acute behavioral and CNS responses to a single exposure to endotoxin or typhoid vaccine and even more convincingly by the many studies examining the biological and behavioral effects of chronic immune activation secondary to treatment with the cytokine IFN- $\alpha$ for either cancer or hepatitis C virus infection (Capuron et al, 2002, 2003a, 2003b, 2005, 2007, 2009; Wichers and Maes, 2004; Wichers et al, 2005b, 2006, 2007; Majer et al, 2008; Harrison et al, 2009a, 2009b; Lotrich, 2009; Lotrich et al, 2009; Prather et al, 2009; Raison et al, 2009, 2010a, 2010b, 2010d; Eisenberger et al, 2010a, b; Franzen et al, 2010; Felger et al, 2011, 2012). Importantly, the induction of depressed mood in response to both acute (ie, typhoid vaccine) and chronic (ie, IFN- $\alpha$ ) immune stimulation has been associated with increased concentrations of circulating inflammatory cytokines (Wright et al, 2005; Raison et al, 2010a). Also consistent with the ability of immune activation/inflammation to negatively impact mood is the fact that the risk of developing MDD, increases following significant infections (Benros et al, 2013; Gunaratne et al, 2013; Bornand et al, 2016). Finally, a recent meta-analysis confirms findings from a number of individual studies that elevated levels of circulating inflammatory biomarkers predict the future development of depression in currently non-depressed individuals, even when controlling for other depressive risk factors (Valkanova et al, 2013).

Increased inflammatory activity has been the most replicated immune change associated with MDD, but there is no a priori reason why this should be the only adaptive immune pattern associated with depression that enhanced pathogen-host defense. A clear prediction of PATHOS-D theory is that as novel innate immune antipathogenic mechanisms are identified, they will be found to be enhanced in depressed individuals. For example, recent studies indicate that antimicrobial peptides upregulated by inflammatory cytokines (eg, ribonuclease 7 , psoriasin, and human $\beta$-defensin-2 and 3; Harder et al, 2007) are increased in the skin of patients with inflammatory skin conditions, such as atopic dermatitis and psoriasis (Harder and Schroder, 2005; Harder et al, 2010), that are comorbid with MDD (Gili et al, 2010; Yang et al, 2010). One would expect a similar increase in these peptides-although perhaps to a lesser degree-in medically healthy individuals with MDD.

\section{RISK FACTORS FOR DEPRESSION SHOULD INDUCE THE SAME PATTERNS OF IMMUNE ACTIVITY SEEN IN MDD}

The best replicated risk factors for MDD in the modern world have been repeatedly associated with the same changes in immune functioning that are observed in MDD (Raison, et al, 2010c). This is especially apparent in relation to associations between these risk factors and increased inflammation; however, stress-which has been the most extensively studied-has also been repeatedly associated with other immune changes seen in MDD (Herbert and Cohen, 1993a, b). Taken at face value, these associations appear to provide strong support for PATHOS-D. However, it is important to note that a number of these factors-such as obesity, sedentary lifestyle and processed foods-are artifacts of modern lifestyles, and therefore are unlikely to have evolved to activate depression as a result of being 'early warning signs' of impending infectious morbidity/mortality in the environment of evolutionary adaptiveness (EEA), as would be predicted by PATHOS-D.

However, at least two proinflammatory risk factors for MDD—-medical illness and psychosocial stress-are certainly ancient and may well have evolved an association with depression as a result of inducing immune changes that enhanced survival in the EEA. PATHOS-D proposes that depression evolved out of sickness, so it is no surprise that robust associations have been seen between medical illness and increased rates of depression in all cultures examined (Moussavi et al, 2007). Because cytokines are primary drivers of sickness, it is also no surprise that medical illnesses are typically characterized by increased inflammation, nor that increased levels of inflammatory cytokines in medically ill patients are associated with an increased risk for depression (Musselman, 2001).

On the other hand, it is not immediately apparent why psychosocial stressors should so reliably activate inflammatory pathways in animals and humans when these types of adversities are not in and of themselves associated with either an infectious challenge or an immune stimulus. Indeed, it has become so commonplace to say that stress increases inflammation that it is easy to lose track of what a remarkable thing this is. Consider the Trier Social Stress Test (TSST) in which study participants are charged with giving a personally meaningful speech and doing mental arithmetic in the presence of a judgmental panel. Predictably, the threatened subject experiences a classic fight or flight response characterized by an increased heart rate and blood pressure and an increased release of cortisol and catecholamines. However, the TSST also activates key intracellular inflammatory transcription pathways (eg, nuclear factor-kappa $\beta$ (NF- $\kappa \mathrm{B})$ ) within peripheral blood mononuclear cells and dramatically increases circulating levels of inflammatory cytokines, such as interleukin (IL)-6 (Bierhaus et al, 2003; Pace et al, 2006a; Carpenter et al, 2010). Moreover, individuals with known risk factors for developing depression (eg, early-life adversity) show larger 
inflammatory responses to laboratory psychosocial stressors than do others (Pace et al, 2006a; Carpenter et al, 2010), and the larger the inflammatory response to the stressor, the more likely the subject is to develop depression over the ensuing months (Aschbacher et al, 2012). In essence, the body mounts an immune response, not against a pathogen, but against a threat to the subject's self-esteem.

Theories that view depression as having evolved to serve adaptive social purposes do not yield easy explanations for why non-infectious stressors should activate peripheral inflammatory pathways. On the other hand, PATHOS-D suggests a straightforward and parsimonious explanation. Because the vast majority of stressors in mammals over evolutionary time boiled down to risks inherent in hunting, being hunted or fighting conspecifics in dominance hierarchies for reproductive access/status, it is not surprising that these states are also circumstances in which the risk of pathogen invasion-and subsequent death from infectionwas greatly increased as a result of traumatic opening of the protective skin barrier from wounding (DiPietro, 1995). Such wounding is common in social species and was a significant source of morbidity and mortality among humans in the ancestral environment, and indeed well into the historical period (Ross et al, 2009; Eshed et al, 2010; Pinker, 2011). In ancestral environments, the association between stress perception and risk of subsequent wounding was reliable enough that evolution, operating by the so-called 'smoke detector' principle, favored organisms that prepotently activated inflammatory systems in response to a wide array of environmental threats and challenges (including psychosocial stressors), even if this activation was often a 'false alarm.' As noted by Dhabhar-'stress perception by the brain may serve as an early warning signal to activate the immune system in preparation for a markedly increased likelihood of subsequent infection' (Dhabhar, 2009). And while chronic stress is best known to suppress certain aspects of immune function (ie, natural killer cell activity, circulating T-cell subsets; Herbert and Cohen, 1993c), the types of acute and/ or psychosocial stressors most likely to be associated with immediate risk of wounding and hence infection activate both innate and adaptive immunity (Quan et al, 2001; Bierhaus et al, 2003; Avitsur et al, 2005; Viswanathan et al, 2005; Pace et al, 2006b; Steptoe et al, 2007; Joachim et al, 2008; Bailey et al, 2009; Rosenberger et al, 2009; Mays et al, 2010; Powell et al, 2010).

That non-immune stressors can activate inflammationand do so via multiple mechanisms including activation of the intracellular inflammasomes-is now firmly established (Miller and Raison, 2015). However, PATHOS-D also predicts that stress-induced immune changes should produce an overall enhancement of pathogen-host defense and especially anti-bacterial defense given that these organisms are the chief cause of wound-related infections. This has yet to be proven or disproven, but significant animal data suggest that psychosocial stressors-even when recurrentcan enhance host defense mechanisms and improve immune function. Using a repeated social defeat stress paradigm
(SDR), Sheridan and colleagues have shown that stress primes multiple aspects of the rodent host defense repertoire. SDR increases the bactericidal activity of splenic macrophages through a Toll-like receptor-dependent pathway; (Bailey et al, 2007) enhances the innate immune response to a primary HSV-1 infection in the cornea and trigeminal ganglia; (Dong-Newsom et al, 2010) primes dendritic cells and augments clonal expansion of CD8(+)T cells during primary influenza A viral infection with a resultant enhancement of adaptive immunity and viral clearance; (Powell et al, 2010; Mays et al, 2012) and activates natural killer cells (Tarr et al, 2012b). To our knowledge, none of these effects have been directly examined in humans, but it is intriguing to note that improved functional recovery following knee surgery has been associated with an increase in the type of immune cell redistribution effects that are known to be induced by acute stress in animals (Rosenberger et al, 2009).

Also relevant to the hypothesis that stress-induced activation of inflammation provides pre-potent protection against pathogens is work by Cole and colleagues demonstrating that social isolation is associated with an immune signature well-tailored to the types of infectious challenges that would most likely have resulted from ostracism in ancestral environments. Individuals who perceive themselves as chronically socially isolated (ie. lonely) show a pattern of gene transcription in leukocytes characterized by increased expression of inflammatory pathways crucial for protection against bacteria with a concomitant decrease in the expression of genes important for antiviral immunity, especially interferon response genes (Slavich and Cole, 2013). Consistent with these findings, individuals with high trait sensitivity to social disconnection produce greater blood levels of proinflammatory cytokines (TNF and IL-6) and increased expression of inflammatory genes in response to an endotoxin stimulus (Moieni et al, 2015a). Similarly, study participants who responded to an fMRI-based social exclusion paradigm with greater activity in the dorsal anterior cingulate cortex and anterior insula-brain regions that have previously been associated with processing rejection-related distress and negative affect-also responded to a laboratory psychosocial stress test with increased salivary production of the inflammatory biomarker soluble TNF- $\alpha$ type II receptor (Slavich et al, 2010).

As Slavich and Cole, (2013) have observed, this pattern of findings in response to social isolation (ie, increased inflammation/reduced antiviral immunity) may well have evolved to optimize immune responses to threats from environmental pathogens associated with wounding/starvation that would have been the primary risk for infectious morbidity/mortality in the EEA for individuals with diminished human-to-human contact. Because ostracism was an almost certain death sentence in ancestral environments, the inflammatory response induced by social isolation/exclusion can be seen as a modern vestige of what once served as an immunological ostracism detection system that worked in concert with other ostracism detection systems described in 
the literature (Spoor and Williams, 2011) to encourage individuals to endure the costs of group existence during the long years of human evolution. This hypothesis might help explain the recent finding that cytokine activation via exposure to endotoxin induces feelings of social disconnection, especially in females. (Moieni et al, 2015) This phenomenon might reflect an evolved and adaptive feedforward mechanism whereby the risk of social exclusion induced a prepotent inflammatory response that then fostered a further sensitivity to the risk of ostracism. And this mechanism may be more apparent in modern females because the offspring of ostracized mothers would have been less likely to survive than those of ostracized fathers (Sear and Mace, 2008). On the other hand, the increased balance of antiviral to anti-bacterial/inflammatory gene expression seen in more socially integrated individuals would have been more optimal for providing protection against more recent viral infections that spread from person to person but that only became widely lethal (and thereby exerted greater selection pressure) with the increased population density that became the norm after the development of agriculture in the first epidemiological transition.

\section{THE ASSOCIATION BETWEEN DEPRESSION AND INFLAMMATION SHOULD BE ANCIENT}

If we assume that a chronic inflammatory response is the most common immune profile associated with MDD, then PATHOS-D predicts that this association should be ancient, because it is this immune response and its associated depressive symptoms that enhanced survival and reproduction via reduced pathogen-related mortality. Strong evidence for this comes from innumerable studies in mice and rats showing that inflammatory cytokines and their stimulators induce depressive and anxiety-like behavior (Dantzer et al, 2008a), as well as studies indicating that even when induced by psychological stress, these behavioral responses are dependent upon cytokine activation-especially the induction of IL-1- $\beta$ in the CNS (Goshen and Yirmiya, 2009). The fact that primate and rodent lineages separated from each other in the time of the dinosaurs strongly suggests that the rudiments of the immune-depression link were laid down early in mammalian evolution, if not earlier.

However, not all data support an ancient or universal link between inflammation and depression, nor is PATHOS-D the only evolutionary theory that might account for such a link if it in fact exists. Indeed, it is increasingly clear that numerous conditions in the modern world have dysregulated immune functioning in ways that promote autoimmunity and chronic inflammation, while simultaneously reducing any adaptive advantage that might be inherent in either the inflammatory response or MDD (Raison et al, 2010c). This scenario opens the possibility that the association between inflammation and depression is a non-adaptive by-product of first world environmental and social conditions, rather than something inherent in either our genetic or behavioral make-up. Said differently, the link between chronic inflammation and MDD may not reflect an evolved adaption, but rather represents an example of non-adaptive environmental mismatch, defined as a state of disequilibrium whereby a trait that enhanced reproductive fitness in the environment in which it evolved becomes maladaptive in another environment.

Of all the modern environmental conditions that have altered associations between immune function and behavior, none has received more attention than our changed relationships with a huge range of microorganisms that were ubiquitous in the EEA, but that are largely missing from the industrialized world. Unlike potentially lethal pathogens, most of which produced either immunity or death, many of the now-absent organisms were best dealt with via the development of immune tolerance, either because the organisms were beneficial (eg, the microbiota), harmless (eg, many environmental organisms), infectious but not lethal (eg, hepatitis A virus) or potentially harmful but not easily cleared by the immune system without excessive tissue damage (eg, many helminths). The central insight of recent iterations of the 'hygiene hypothesis' (such as the 'Old Friends' Hypothesis of Rook) is that because the immune system had to learn to tolerate these organisms (as opposed to clearing them from the body), they became 'teachers of tolerance,' especially during childhood development when their absence predisposes individuals in industrialized societies to develop a host of allergic, asthmatic, autoimmune, and psychiatric pathologies (Raison et al, 2010c).

In a way that seems more than metaphorical, this notion points toward another way that depression may be about relationships. We need to look no further than the impact of bereavement on mood or the strong association between the death of a parent in childhood and the development of MDD in adulthood to see that human relationships characterized by loss can be profoundly depressogenic (Berg et al, 2016). Increasing evidence suggests the same is true of our relationships with the microbial world. Via dysregulated inflammatory activity, our moods are haunted by the loss of 'old friend' organisms of which most of us have no conscious knowledge. Again, like our relationships with other humans, our relationships with bacteria, viruses, and parasites can be understood as comprising various degrees of competition and cooperation/collaboration. PATHOS-D suggests that the link between depression and immune activation primarily reflects the competitive element in these relationships. The evolutionary mismatch model suggests the opposite: that the link between depression and immune activation reflects the failure of the modern world to honor many ancient and mutually beneficial collaborations. So, can available data help us determine which theory is better supported?

To our minds, the strongest data that support evolutionary mismatch, while simultaneously arguing against PATHOS$\mathrm{D}$, come from the ground-breaking work of McDade and colleagues who have examined associations between stress, mood and inflammation in non-industrialized environments. Working in the Philippines and lowland Ecuador, 
they have shown that patterns of inflammation observed in the West do not necessarily translate to less-developed environments with significantly higher pathogen exposure and infectious mortality. In industrialized contexts, the concentrations of peripheral inflammatory biomarkers show significant intra-individual stability, with some individuals demonstrating chronically elevated levels of these biomarkers (Macy et al, 1997; Ockene et al, 2001). Moreover, factors other than pathogen exposure (especially obesity) have been repeatedly shown to upregulate inflammation. McDade et al, (2009) found that neither of these pertain in more traditional societies. In the Philippines levels of CRP were significantly lower, and levels of the anti-inflammatory cytokine IL-10 significantly higher, than are typically observed in Western contexts, and these associations were not accounted for by differences in body mass index between the populations (McDade et al, 2009). In lowland Ecuador among the indigenous Shuar people, levels of CRP were found to vary widely within the same individuals, showing a pattern of rapid rise to high levels in response to acute infection and then dropping to often undetectable levels upon infection resolution (McDade et al, 2012b). An even more direct challenge to PATHOS-D predictions came from findings that depression was not associated with elevated CRP in the Philippines and that associations between both current and childhood stressors (ie, death of a parent) and inflammation were only apparent in the sub-population in the Cebu region that had been raised in more hygienic environments (McDade et al, 2012a). Individuals with high levels of microbial exposure in infancy showed no such associations. Taken together, these data suggest that high microbial exposure early in life-such as would have been normative across human evolution-may hone the immune response to be more specific for pathogen exposure and less generalized to the types of psychosocial stress that so reliably induce depression. Under these evolutionarily normative environments, the links between inflammation and MDD that are so apparent in the West would not exist.

However, these findings must be balanced against more recent work conducted in the lowland jungle of Bolivia among the Tsimane Amerindians, a small-scale society composed of lean forager-horticulturalists with a short average lifespan who live in a high-pathogen environment and thus have significant microbial priming in infancy (Stieglitz et al, 2015b). In all these ways the Tsimane represent a reasonable approximation of environmental and social conditions prototypically confronted by humans in the EEA. Working among these people, Stieglitz et al. (2015b) examined whether a syndrome recognizable as MDD exists, and if it exists, whether it is associated with increased inflammatory biomarkers. Results indicated that a depressive syndrome identical to that seen in the industrialized world exists among the Tsimane, and is associated with the same risk factors that have been observed everywhere else in the world: reduced health (indexed as functional disability) and psychosocial stress (indexed by social conflict, especially with non-kin; Stieglitz et al, 2015a). When examined as a binary construct based on a median split in symptom scores, depression was also associated with significantly increased serum concentrations of IL-6, TNF, and CRP but not IL-1- $\beta$ (Stieglitz et al, 2015b), replicating the overall pattern of metaanalytic findings from studies conducted in industrialized societies. These associations remained after adjustment for age, body mass index, and high leukocyte count (likely indicative of current infection), and associations were observed across a wide range of depressive symptoms.

As our discussion of this prediction suggests, currently available data provide a split decision on whether associations between depression and inflammation are ancient and hence potentially adaptive, or are of recent origin and thus likely a result of non-adaptive evolutionary mismatch. One can only mourn the fact that the theoretical perspectives and technology necessary to resolve this issue were not available in the middle years of the 20th Century when a range of hunter-gatherer groups on several continents had yet to be driven to extinction by the inexorable onrush of the modern world. PATHOS-D theory engenders a sense of urgency to examine this issue in the remnant small-scale societies that remain. Two types of studies would be especially relevant. First, it would be of great interest to conduct the equivalent of Trier Social Stress Tests in these societies to examine whether objectively induced psychosocial stress activates inflammatory pathways as it does in the West. Second, it would be important to examine whether the administration of cytokine activators (ie, endotoxin, typhoid vaccine or longer-term treatment with IFN- $\alpha$ ) produce depressive symptoms as they do in the industrialized world. If individuals living in environments more closely aligned with prototypical conditions in the EEA showed inflammatory responses to psychosocial stress and if they responded to immune stimulation with depression, strong evidence in support of PATHOS-D would have been obtained.

\section{THE TYPES OF IMMUNE CHANGES SEEN COMMONLY IN MDD SHOULD HAVE PROMOTED SURVIVAL IN THE HIGH- PATHOGEN ENVIRONMENTS IN WHICH HUMANS AND THEIR ANCESTORS EVOLVED}

From a PATHOS-D perspective there is no a priori reason that MDD should be associated with increased inflammation, only that MDD be associated with genes, physiology and behavior that-on average-decreased infectious mortality across human evolution. The fact that a subset of patients with MDD demonstrate increased inflammation implies the hypothesis that if depression is associated with increased inflammation, and if depression evolved as an adaptive pathogen-host defense strategy, then increased inflammatory activity should have produced an overall survival benefit in high-pathogen ancient environments, if indeed the association between depression and inflammation was adaptive in the EEA. For this idea to be credible two things are required: first depression should enhance host defense, 
and second inflammation should enhance host defense. On the face of it, neither appears to be true, given significant evidence that both depression and inflammation appear to increase-rather than decrease-vulnerability to infection (Zorrilla et al, 1996; Evans et al, 2002; Cruess et al, 2003; Raison et al, 2005; Doering et al, 2008; Faulkner and Smith, 2008; Leserman, 2008; Leutscher et al, 2010; Andersson et al, 2016; Doran et al, 2002). Here we consider the question of whether inflammatory activity provided protection against infectious mortality.

For at least 2000 years it has been recognized that inflammation is essential for human health and a necessary ingredient of our ability to adequately fight infections. We now know that the larger innate immune response-of which inflammation is a core component-provides both direct and rapid protection against all classes of pathogens and has a crucial role in activating slower, but more definitive acquired immune responses. However, studies in recent years have found that the relationship between the innate and acquired immune systems follows the laws of cooperation and competition that define all evolved relationships. Especially under conditions of limited energy availability or simultaneous infectious risk from multiple pathogens, immune function can become characterized by trade-offs between these two branches of immunity, such that resources invested in one, mean reduced functionality of the other (McDade et al, 2016). Consistent with this notion, chronic inflammation can actually suppress $\mathrm{T}$ - and B-cell function through various mechanisms (Cope et al, 1997; Moraska et al, 2002; Cope, 2003; Clark et al, 2005; Muller et al, 2008; Vaknin et al, 2008; Eleftheriadis et al, 2009; Blume et al, 2011), and rates of infection are often increased -not decreased-in autoimmune conditions characterized by chronic inflammation (Doran et al, 2002). However, PATHOS-D theory requires only that across evolutionary time the patterns of enhanced inflammatory activity characteristic of depression provided overall survival benefits that outweighed any costs imposed by associated reductions in other aspects of immune functioning.

Some evidence for this possibility comes from studies conducted by Westendorp and colleagues in Ghana and the Netherlands. These researchers observed that cytokinestimulated production of TNF- $\alpha$ declines with age in the Netherlands, a country with a low infectious burden, but does not decline with age in Ghana, a country with high rates of infection (ie, $85 \%$ of Ghanan study participants were infected with malaria; May et al, 2009), suggesting that increased proinflammatory cytokine production-as observed in MDD-promotes survival under conditions of high-pathogen burden (Drenos et al, 2006). More definitive evidence for this possibility comes from a second Ghanian study that more directly examined the impact of pathogen exposure on the association between inflammation and survival. Ghana is a country in which some regions have pure water available from boreholes, whereas other regions must rely on heavily contaminated rivers for drinking water. As would be expected, death rates from infection are far higher in regions that utilize rivers than in areas where borehole-obtained water is available. Consistent with the prediction that increased inflammatory signaling is protective in the high-infection environments that were common during human evolution (and especially common since the origin of agriculture and the rise of cities; Armelagos et al, 2005), a haplotype of the IL-10 gene associated with increased inflammation was found to be significantly more prevalent in populations that relied on river water than in populations that drank from boreholes-suggesting positive selection driven by enhanced pathogen protection (Kuningas et al, 2009). Consistent with this possibility, during a fiveyear follow-up period, the high-inflammation IL-10 haplotype was associated with reduced survival in individuals who drank clean water from boreholes, but increased survival in populations exposed to high levels of pathogens as a result of drinking river water (Kuningas et al, 2009).

We have already noted that depression is associated with increased circulating inflammatory biomarkers in the forager-horticulturist Tsimane people of lowland Bolivia (see Prediction 3). Researchers also conducted ex vivo stimulation studies with endotoxin and phytohemagglutinin (PHA; to assess response capacity of both the innate and acquired immune systems, respectively) and found that Tsimane individuals with high levels of depression produced greater levels of IL-1- $\beta$, IL-6, and TNF in response to both endotoxin and PHA, even when excluding individuals with leukocyte counts suggestive of current infection (Stieglitz et al, 2015b). Interestingly, this pattern is different from the suppression of mitogen-stimulated immune responses commonly observed in depressed patients in the Western world (Herbert and Cohen, 1993a), which may point to yet another way in which modern conditions have disabled previously adaptive associations between depression, immune function, and pathogen-host defense. Nonetheless, whether the increased mitogen-stimulated inflammatory cytokine response observed among depressed members of Tsimane society would translate to enhanced protection against pathogens remains unknown.

Multiple facets of the modern world, from antibiotics to refrigeration and paved surfaces have profoundly reconfigured our relationship with the microbial world in ways that have reduced the benefits of inflammation and increased its costs (Drenos et al, 2006; Raison et al, 2010c). Nonetheless, even in an environment so radically different from that in which humans evolved, data link increased inflammation with improved outcome in the context of at least some infections. For example, in a large study of consecutive patients admitted to hospital with fever, elevations in plasma concentrations of the anti-inflammatory cytokine IL-10-as well as the ratio of IL-10/TNF- $\alpha$-were associated with increased mortality (van Dissel et al, 1998) and increased IL-10 production late in the disease course predicted reduced survival following infection with the pandemic A/H1N1/2009 influenza virus (Bermejo-Martin et al, 2010). As these findings would predict, alleles of the IL-10 gene-such as $-1082 \mathrm{G}$ - associated with higher IL-10 production appear to 
promulgate poor infectious outcomes. For example, the $-1082 \mathrm{G}$ allele predicts increased symptom severity and mortality in the context of community acquired pneumonia (Gallagher et al, 2003) and is associated with reduced antibody responses to tetanus, influenza and hepatitis B virus (HBV) vaccines (Hohler et al, 2005; Corsini et al, 2006; Li et al, 2007). Families with a member who died from meningococcal disease were characterized by increased production of IL-10 and reduced production of TNF- $\alpha$ when compared with families with a member who had bacterial meningitis but survived (Westendorp et al, 1997) and elevated CRP has been associated with increased survival in children with meningococcal sepsis (Joosten et al, 2000). The IFN- $\gamma+874 \mathrm{~T}$ allele increases production of this Th1 inflammatory cytokine via enhanced binding of NFKB (Pravica et al, 1999, 2000) and protects against Mediterranean Spotted fever (Forte et al, 2009). Multiple studies and a large meta-analysis find that the $\mathrm{T}$ allele also protects against the development of tuberculosis on the individual (Pacheco et al, 2008) and population levels (Larcombe et al, 2008). In individuals with active tuberculosis, the $\mathrm{T}$ allele reduces severity and risk of disseminated disease (Ansari et al, 2009). The $\mathrm{T}$ allele also reduces the risk of leprosy (Cardoso et al, 2010), severe acute respiratory syndrome (SARS; Chong et al, 2006), and Chagas disease (Torres et al, 2010). Conversely, the low-producing $+825 \mathrm{~A}$ allele predisposes for hepatitis $\mathrm{B}$ and $\mathrm{C}$ persistence and negatively impacts clinical course of the disease (Gao et al, 2009). Consistent with these findings, reduced peripheral blood mononuclear cell production of IFN- $\gamma$ and IL-12 is associated with increased severity of respiratory syncytial virus symptoms in infants under one year of age (Pinto et al, 2006).

\section{THE SIGNS AND SYMPTOMS OF MDD SHOULD SERVE PATHOGEN DEFENSE FUNCTIONS}

The association of depression with increased circulating levels of proinflammatory cytokines and CRP does not easily lend itself to social explanations for the high prevalence of either MDD or putative depressogenic risk alleles. On the other hand, this association is foundational to the proposal that depression evolved to serve pathogen-host defense functions. However, if this is indeed the case, why should we expect the immune changes seen in depression to be limited to circulating cytokines or CRP? In the context of innate immune activation, cytokine stimulation forms only part of a larger phenomenon that comprises the acute phase response (APR). As noted in a recent review (LeGrand and Alcock, 2012), the APR is a somewhat paradoxical phenomenon, given that many of its features inflict significant energetic costs (eg, fever), hamstring immune responses (eg, iron sequestration, zinc, and tryptophan depletion), or produce behaviors likely to reduce attractiveness to potential mates, induce loss of social status or increase the risk for predation (eg, lethargy, psychomotor slowing, and social withdrawal), all of which would be expected to impair, rather than enhance, host survival, and reproduction. And while fever has been shown to enhance immune function while simultaneously contributing directly to pathogen killing, no direct immune benefits have been shown for many other APR features. A potential resolution to this enigma has been offered recently under the rubric of 'immune brinksmanship', which suggests that many APR features-such as iron sequestration and reduced zinc availability-have evolved to make the host environment less optimal for invading organisms, given that these minerals are essential nutrients for microorganisms, without which they can neither replicate nor survive (LeGrand and Alcock, 2012). From this perspective the APR can be seen as being, in part, a strategy that risks damage to the self, but that is likely to kill the offending agent before it kills the host. A comprehensive vision of the APR sees some of its elements as serving direct anti-pathogen functions (eg, leukocytosis), some as serving to reallocate energy to the immune system (eg, psychomotor slowing, somnolence) and some as serving 'immune brinkmanship' functions.

Studies suggest that, as a group, medically healthy individuals with depression demonstrate multiple biological and behavioral stigmata of an APR (Jimenez-Fernandez et al, 2015). For a full listing of elements of the APR that have been associated with MDD in medically healthy individuals, see Supplementary Table S2. Importantly, at least one group has found that the APR in medically healthy adults with MDD is associated with increased levels of IL-6, suggesting that the APR is indeed part of a larger pathogen-host defense immune response (Maes et al, 1995; Sluzewska et al, 1996).

Moreover, if psychosocial stress serves as an 'early warning system' for increased danger of impending wounding and subsequent infection, PATHOS-D would predict that psychosocial adversity should also be associated with an APR over and above activation of cytokines. Consistent with this possibility, stress in animals reduces gastrointestinal absorption and blood levels of iron (Zhao et al, 2008; Chen et al, 2009) and in human males a 5-day intense psychological stressor ('Hell Week') reduced blood levels of iron, zinc, and albumin (Singh et al, 1991), as would be predicted if stress induces an APR. Psychological stress has also been reported to elevate core body temperature in animals and humans (Soszynski et al, 1996; Kaneda et al, 2009; Hayashida et al, 2010), an anti-pathogen defense mechanism that is most effective in conditions of low host iron availability (Kluger and Rothenburg, 1979). That these changes serve immune purposes is suggested by findings that in animals, stressinduced hypoferremia and hyperthermia are associated with stress-induced increases in IL-6 (Soszynski et al, 1996; Zhao et al, 2008); however, other mechanisms may also be active, including hypothalamic activation of brown fat (Kataoka et al, 2014). Because at least some biological changes associated with the APR have been shown to have important roles in pathogen-host defense, their presence in depression would be strongly predicted by PATHOS-D, and their 
absence would strongly argue against the validity of this approach. On the other hand, their presence in MDD is not parsimoniously explained by theories that focus on potential social benefits of depression. In what ways would elevated body temperature or reduced iron availability aid in negotiating relationships with other humans? Similarly, if depression is simply a non-adaptive phenomenon, why would such ancient, highly conserved and highly complex physiological responses be associated with the disorder?

Inseparable from the physiological aspects of the APR, immune activation also produces a suite of behavioral responses known as sickness behavior that has been retained across vertebrate evolution and that shares many features in common with the symptoms of MDD (Dantzer, 2006; Dantzer et al, 2008b). These symptoms include lethargy/ fatigue, psychomotor slowing, altered sleep, loss of appetite, anhedonia, and social withdrawal. Although it is clear that the symptoms of depression can arise from a wide variety of divergent causes-including internally generated thought patterns-PATHOS-D proposes that MDD initially evolved out of sickness behavior. Circumstantial evidence for this type of close relationship between sickness and MDD come from several sources. For example, data suggest that many people cannot accurately identify whether they are developing depression or an infectious illness early in the course of either condition (Ratcliffe, 2013). Similarly, sickness in the first week of treatment with the cytokine IFN- $\alpha$ strongly predicts the development of cognitive/emotional symptoms of depression over the ensuing 6 months of therapy (Wichers et al, 2005a). Finally, if inflammation induces sickness and if depression evolved out of sickness, inflammation might be expected to be more strongly associated with the symptoms most often shared by sickness and depression, rather than symptoms such as sadness and guilt/feelings of worthlessness that are more specific to MDD. Supporting this possibility, an early report found that the acute phase protein haptoglobin correlated with psychomotor retardation, sleep disturbance, anorexia/weight loss, and anhedonia (Maes et al, 1993). More recently, a large population-based study $(N=15071)$ reported that CRP was more strongly associated with sleep abnormalities, fatigue, and appetite changes than with MDD symptoms less common in the context of sickness (Jokela et al, 2016). In a group of patients with MDD, increased circulating levels of IL- 6 and monocyte chemoattractant protein-1 were positively associated (and levels of IL-10 were negatively associated) with objectively measured psychomotor slowing (Goldsmith et al, 2016a), and elevated plasma CRP was associated with reduced functional connectivity between the ventromedial prefrontal cortex and ventral striatum. These changes in functional connectivity mediated associations between increased CRP and anhedonia and psychomotor slowing (Felger et al, 2015).

Evolutionary processes do not produce perfect products, and all evolved adaptive mechanisms come with associated costs and trade-offs. If indeed MDD is conceptualized as a condition evolved from, and 'designed' to serve the same purposes as, sickness, the obvious question is what pathogen- related survival and reproductive benefits accrue from depressive symptoms that offset their costs. That depression reduces fitness in modern environments has often been remarked upon; however, the costs across evolutionary time of the types of prolonged sickness behaviors that comprise MDD have also likely been substantial. As part of the APR, sickness exacts significant metabolic costs that limit energy available to other tasks essential for survival and reproduction. In many species, including humans, even subtle signs of sickness promote avoidance behavior from conspecifics (Schaller, 2011). Over and above the suppressive effect of inflammation on sexual functioning, individuals who appear sick are judged to be less attractive and hence are less likely to find high-quality mates. In hierarchical social groups the display of sickness risks loss of social status, with associated reductions in survival and reproductive access. Finally, sickness increases the risk of predation (Schaller, 2011).

One possibility is that the PATHOS-D perspective is exactly backwards, and in fact depression is a maladaptive consequence of the benefits of acute sickness. Perhaps depression is akin to other chronic conditions, such as HIV and autoimmune diseases, in which ongoing inflammation, rather than providing benefit, actually increases the risk of infection and/or infectious mortality. Many studies associating MDD with increased infectious morbidity in the modern world would support this possibility (Zorrilla $e t$ al, 1996; Evans et al, 2002; Cruess et al, 2003; Raison et al, 2005; Doering et al, 2008; Faulkner and Smith, 2008; Leserman, 2008; Leutscher et al, 2010; Andersson et al, 2016). If true, this removes pathogen-host defense as an explanation for the conundrum of why genes that contribute to MDD have been retained across hominid evolution.

Or it may be that by inducing social withdrawal, depression provides an adaptive advantage for individuals at increased risk of infection as a result of immune functioning that for one reason or other is sub-optimal. This is the position taken by Kinney and Tanaka (2009) in proposing that depression evolved as an adaptive response to cope with pathogens (Anders et al, 2013). In contradistinction, PATHOS-D suggests that-whatever its costs in relation to specific pathogens-depression was not primarily a compensation for immune inadequacy, but rather enhanced overall survival in the EEA via its association with physiological and behavioral changes that reduced the impact of infectious agents on reproductive success. Said differently, in conditions characterized by a heightened risk for infectious mortality, such as occur during active infection or when environmental adversity signals an increased risk for wounding or other processes that increase the risk of infection (ie, starvation secondary to ostracism), the generalized innate immune activation and symptoms associated with depression provided a net survival benefit, whatever their other costs in terms of immune or social trade-offs. Importantly, this perspective does not require that depression be the only way for humans to adaptively cope with infectious risk only that it was adaptive enough for its genetic 
underpinnings to be retained in the human genome at a level significant enough for MDD to be with us today.

From a PATHOS-D perspective, MDD in response to infection or tissue trauma provides the same types of survival benefits as does sickness behavior. In response to stress, depression can be seen as proactive physiological/behavioral sickness behavior-a type of 'just in case' condition that keeps an individual in a state of pathogen defense readiness. Proinflammatory cytokine activation in response to either infection or stress induces a behavioral state of conservationwithdrawal (Engel and Schmale, 1972; Eisenberger et al, 2010b; Hannestad et al, 2011) characterized by depressed mood, anhedonia, psychomotor retardation, fatigue, social avoidance, and anorexia (Capuron et al, 2002; Dantzer et al, 2008b; Majer et al, 2008; Irwin and Cole, 2011). This state is an integral component of depressive disorders and has been widely considered to develop in the context of infection and/ or tissue injury as a means of marshalling limited metabolic resources for the expensive tasks of immune activation, fever generation and tissue repair (Hanff et al, 2010).

In addition to energy allocation, conservation-withdrawal symptoms may have also proved adaptive by reducing interpersonal contact and thereby limiting infectious exposure (Kinney and Tanaka, 2009). In the paradigm proposed by Kinney and Tanaka (2009) this is seen as an evolved compensatory mechanism to cope with immunodeficiency. However, it is equally possible that the infectionavoidance benefits of social withdrawal evolved as a complement to its metabolically valuable infection-fighting benefits. Indeed, the more survival and reproductive benefits accrue for any one trait the more likely its genetic antecedents are to be retained and to spread in the population. Because humans in the EEA lived in small coalitional groups of genetically related individuals, the logic of inclusive fitness suggests that social withdrawal might have been adaptive for an individual's genes by reducing the risk of infection in kin, even if such withdrawal limited the provision of much needed care from others and thus reduced individual survival (Cole, 2006; Schaller and Murray, 2008). Indeed, given evidence that merely viewing pictures of a sick individual activates the viewer's innate immune system (Schaller et al, 2010), it may be that by prepotently activating the innate immune responses in one's kin, depression served as an early warning system for increased infectious risk. In this regard, it is interesting to note that associating with depressed individuals increases the risk of developing depression oneself (Fowler and Christakis, 2008), exactly as would be predicted if depression served as an early warning signal to others of infectious risk and if depression enhanced host pathogen defense by priming the innate immune system. A clear prediction of this line of reasoning that awaits testing is that viewing images of depressed individuals should activate the immune system.

In addition to potential inclusive fitness benefits, any decrement in survival from depression-induced loss of social aid might have been more than offset by reduced risk of exposure to other pathogens while in a vulnerable state due to a pre-existing infection, given that viral infections promote aggressive immune responses to bacterial superinfections that can greatly increase mortality (Degre and Glasgow, 1968; Jakab and Dick, 1973; Jones et al, 1983; Nguyen and Biron, 1999; Molyneux et al, 2003; Beadling and Slifka, 2004; McCullers et al, 2010). Moreover, social withdrawal and reduced environmental exploration might also have promoted individual survival by limiting a depressed individual's contact with immunologically dissimilar out-group members who potentially harbored pathogens against which the depressed person would have had reduced immunity compared to pathogens endemic in the home group (Schaller and Murray, 2008; Thornhill et al, 2009). This idea suggests a hypothesis that to our knowledge has never been tested that MDD should be associated with increased xenophobia. It is intriguing to note, however, that endotoxin administration increased the desire of healthy volunteers to be around individuals they had previously identified as 'support figures' (Inagaki et al, 2015), consistent with the possibility that immune changes associated with depression might have promoted an in-group bias that reduced exposure to more potentially lethal pathogens harbored by members of other social groups. How such an increased desire to associate with in-group members would square with the potential selective advantages of withdrawing from kin to prevent the spread of infection is unknown. Moreover, given that sterile psychosocial stressors also activate inflammation, it is intriguing to speculate that the benefits of seeking support/proximity with kin/in-group members in response to psychosocial dangers may have offset the potential risks of contagion spread as a result of inflammation enhancing prosocial behavior with trusted ingroup members.

With the exception of asthma and allergies, inflammatory conditions typically strike after the age of reproduction, and thus alleles that promote them are subject to minimal selective pressure, even in modern environments (Beekman et al, 2010). Almost certainly, the association between chronic inflammation and these disease states (eg, dementia and cardiovascular disease) serves no adaptive purpose and likely results in large measure from environmental conditions unique to the modern world. However, the relationship between inflammation and depression is quite different, given that the incidence of MDD peaks in the 20-30 s (Eaton et al, 1997; Patten et al, 2006; Kessler et al, 2010), an age of primary reproductive/childrearing responsibilities. In this, MDD is not alone. Schizophrenia and bipolar disorder -conditions with which MDD is genetically linked-are also characterized by increased inflammation and by an average age of onset early in life when the costs of these disease states to survival and reproduction are (and were) likely to be maximal.

Although the current article focuses on unipolar depression, there is no reason to think that depressive symptoms occurring in the context of bipolar disorder would be any less efficacious for pathogen-host defense than the same symptoms when they occur in other contexts, and indeed 
multiple studies demonstrate that bipolar depression is associated with the same types of inflammatory activation that are observed in unipolar MDD (Goldstein et al, 2009). However, what should we make of the fact that multiple studies show that inflammatory markers are at least as elevated-and maybe more elevated-in manic episodes as they are during bipolar depressions (Goldstein et al, 2009)? A proximal answer might point to the fact that mania is associated with many of the same neuroendocrine abnormalities as depression, especially glucocorticoid resistance (Schmider et al, 1995), which is known to release inflammatory pathways from inhibitory control and which has been associated with increased proinflammatory cytokine levels in MDD (Maes, 1999). Moreover, although far less common than depression, full manic episodes have been reported during IFN- $\alpha$ therapy, which produces chronic immune activation, and combinations of depressive and manic symptoms during IFN- $\alpha$ treatment are common (Constant et al, 2005).

However, this type of answer provides no insight into why mania should be associated with increased inflammation. Might the association serve adaptive purposes or is it better considered as an example of antagonistic pleiotropy? Here PATHOS-D offers a novel perspective. Until it becomes disabling, mania increases the types of social and sexual extroversion that may provide direct Darwinian benefits as a result of increased opportunities for reproduction (Berry and Miller, 2001). However, increased social and sexual activity also increase the risk for reduced survival as a result of increased pathogen exposure (Hamrick et al, 2002). In this context, might genes linking inflammation with mania have undergone positive selection by conferring increased protection against the wide range of infections to which manic behavior would have exposed an individual in the EEA? Although highly speculative, this hypothesis produces the clear prediction that the increased inflammation observed in mania should be associated with the symptom of hypersexuality, especially in males, who across evolutionary time would have been more likely than females to benefit in terms of reproductive success from sexual activity with multiple partners. Interestingly, animal data provide some evidence for this possibility, given that cytokine activation suppresses sexual activity in female, but not male, rats (Avitsur and Yirmiya, 1999). However, this hypothesis would be strengthened by evidence that manic behavior itself can elevate inflammation and to our knowledge this type of causal connection has not been investigated.

\section{WHATEVER THEIR OTHER FUNCTIONS, RISK GENES FOR MDD SHOULD SERVE PATHOGEN-HOST DEFENSE}

In a previous publication we provided an exhaustive enumeration of known immune and/or pathogen defense functions for the best-supported risk alleles for MDD derived from genome-wide association studies (GWAS) and meta-analyses of candidate gene studies (Raison and Miller, 2012). These GWAS findings are presented in Supplementary Table S3. In the time since our prior publication, an additional study utilized sparse wholegenome sequencing in a population of Han Chinese females to identify and replicate two novel depression risk loci on chromosome 10, one $5^{\prime}$ to the suirtuin 1 (SIRT1) gene (rs12415800) and one in an intron of the phospholysine phospho-histadine inorganic pyrophosphate phosphatase (LHPP) gene (consortium C (2015)). As with previously identified 'genes of interest,' PATHOS-D predicts that these genes should impact immune function in ways that provided adaptive advantages for pathogen-host defense. In this regard, nothing is known regarding LHPP, but an extensive database attests to multiple immune functions of sirtuin 1, a class III histone deacetylase enzyme that serves as an important sensor of cellular energy and redox states (Supplementary Table S3; Michan and Sinclair, 2007).

In particular, sirtuin 1 has been shown via epigenetic mechanisms to have a key role in limiting the extent and duration of acute inflammation by promoting a shift from inflammation-driven glycolytic activity to 'adaptation-phase' fatty acid metabolism. Sirtuin 1 suppresses nuclear factorkappa B RelA/p65 activity, represses cyclooxygenase 2 gene expression (Zhang et al, 2010b), and induces gene silencing facultative heterochomatin formation at the promotors of proinflammatory genes, including TNF and IL-1- $\beta$, as well as the promotor for hypoxia-inducible factor-1- $\alpha$, a signaling factor important for maintenance of proinflammatory glycolytic activity (Vachharajani et al, 2016). In addition, sirtuin 1, in dependence on NAD+, increases levels of peroxisome proliferator-activated receptor gamma coactivator 1 (PCG-1)- $\alpha$ and $\beta$, which promotes the fatty acid metabolism essential for resolution of the inflammatory response (Fernandez-Marcos and Auwerx, 2011). The end result of these activities is that sirtuin 1 inhibits the transformation of monocytes to macrophages and promotes anti-inflammatory M2 macrophages and regulatory T cells (Treg) at the expense of proinflammatory M1-type macrophages and effector T cells (Liu et al, 2012a; Park et al, 2016). However, conflicting data suggest that in at least some contexts sirtuin 1 may have inflammatory and adaptive immune stimulating effects. For example, sirtuin 1 inhibition has been reported to stimulate Foxp3 expression in Treg (Akimova et al, 2014).

Despite these complexities, evidence of diminished sirtuin 1 activity in medical conditions characterized by chronic inflammation suggest that its function might also be reduced in MDD, especially in patients with elevated peripheral inflammatory biomarkers. However, to our knowledge, no data are available to support or disprove this idea. Similarly, given the association of MDD with chronic inflammation, one would predict that the depression risk allele near the SIRT1 gene should reduce sirtuin 1 activity, if it is found to have a functional effect, which is currently unknown. However, these predictions should be tempered by findings suggesting a complex and contradictory role for sirtuin 1 in 
pathogen defense. In certain contexts, such as the hypoinflammatory phase of sepsis, sirtuin 1 blockade has been reported to reduce bacterial load and enhance survival. Sirtuin 1 blockade has also been shown to inhibit hepatitis B replication in hepatocytes (Ren et al, 2014). Similarly, sirtuin-deficient mice have been shown to demonstrate improved intestinal anti-bacterial defense mechanisms (Lo Sasso et al, 2014). On the other hand, the use of celecoxib to stimulate sirtuin 1 within macrophages resulted in an enhanced ability of ampicillin to clear Staphylococcus aureus from these cells (Annamanedi and Kalle, 2014), consistent with the observation that low levels of sirtuin 1 within macrophages associates with bacterial infection in these cells (Zhang et al, 2010a, 2010b). Sirtuin 1 also appears to be essential for optimal immune clearance of respiratory syncytial virus and has been shown to suppress human T-cell leukemia virus type 1 transcription (Owczarczyk et al, 2015; Tang et al, 2015).

Although a perusal of Supplementary Table S3 highlights the remarkable degree to which SIRT1 and many other potential depression risk alleles impact both immune function and pathogen defense, it should be noted that there is another pathway whereby these risk alleles might enhance pathogen-host defense without directly modulating immune function. If the PATHOS-D proposal that depressive symptoms themselves serve pathogen defense functions is correct, genes that promote these symptoms might have served adaptive purposes in fighting infection via this mechanism alone. For example, in addition to multiple immune effects, sirtuin 1 signaling in the hippocampus appears to have antidepressant effects, given animal data that pharmacologic and genetic inhibition of hippocampal SIRT1 function increases depression-like behaviors in response to stress, whereas SIRT1 activation blocks both the development of depression-related phenotypes and aberrant dendritic structures elicited by chronic stress exposure (Abe-Higuchi et al, 2016). CACNA1C is another putative depression risk gene known to both enhance and impair pathogen-host defense depending on the microorganisms involved (Raison and Miller, 2012). Carriers of the rs 1006737 A risk allele have also been shown in several studies to demonstrate changes in brain function and morphology relevant to MDD (Bigos et al, 2010; Erk et al, 2010; Perrier et al, 2011), again raising the possibility that even genes with known immune effects might enhance pathogen defense either primarily, or synergistically, via the direct induction of depression in response to environmental adversities known to increase the risk for pathogen-induced morbidity/ mortality (ie, stress signaling an increased risk of wounding, active infection; Bigos et al, 2010; Erk et al, 2010; Perrier et al, 2011). Understanding the impact of putative risk genes like SIRT1 or CACNA1C on inflammatory and behavioral responses to psychosocial stress would provide invaluable insight into the question of whether they promote depression and pathogen-host defense via the type of inflammatory activation that is a hallmark of MDD in the modern world.
RISK ALLELES FOR MDD SHOULD NOT BE CONSTANT ACROSS RACIAL/ETHNIC/ CULTURAL GROUPS AS A RESULT OF DIFFERENTIAL EXPOSURE TO PATHOGENS AND ADAPTIVE INTROGRESSION WITH ARCHAIC HUMAN SPECIES

PATHOS-D proposes that depression risk alleles have been maintained in the human genome primarily because, by enhancing pathogen-host defense, they provided a net survival and reproductive advantage. A primary problem that this theory shares with other adaptive explanations for depression is that to date no incontrovertible risk alleles for MDD have been identified. Indeed, most large GWAS have failed to find SNPs that meet genome-wide significance and when such SNPs are found (ie, rs12520799 in DCNP1 and rs76917 in TNF) they are not replicated in GWAS conducted in other populations (Raison and Miller, 2012).

Multiple explanations have been offered for this case of 'missing depression genes,' most often that MDD is heterogeneous in relation to its environmental antecedents, the nature and severity of its symptoms and its disease course; and that therefore it is likely that the condition is a concatenation of numerous as-yet-unidentified more etiologically homogeneous sub-conditions that are likely to be more genetically consistent. Although not dismissing disease heterogeneity as a cause for failure to replicate depressive risk alleles, PATHOS-D offers an additional novel explanation for at least some cases of replication failure. Because pathogens can develop resistance to host immune defenses, or in many cases actually evolve to benefit from these defenses via pathogen manipulation strategies, not all genetically programmed physiological or behavioral pathogen-host defense strategies will be equally effective against all microbes. Because of this, in cultures/societies exposed to different mixtures of pathogens across time, different immune mechanisms will be adaptive, and therefore likely to become linked to depression. Said differently, because of geographic and historical differences in pathogen exposure, we should not expect all human ethnic/racial groups to have benefitted from the same genetically driven pathogen defense strategies and therefore to show the same risk alleles for MDD. Thus, a PATHOS-D perspective suggests that understanding the specific histories of shared and unique co-evolved pathogen-host interactions within and across human societies will be essential for enhancing our understanding of why genotype-phenotype associations observed in one population do or do not replicate across other populations, as well as why certain genetic variants drive physiological processes that induce depression in certain individuals but not in others.

These insights may help account for the intriguing finding that the association between SIR1 nor LHPP SNPs and MDD identified in Han Chinese females was not replicated in European populations (Consortium C (2015)). PATHOS-D would predict that this finding might be accounted for by the fact that SIRT1 and LHPP conferred specific anti-pathogen 
defenses in the Chinese environment that were not relevant in Europe. If so, one would expect the prevalence of the SIRT1 and LHPP risk alleles to be significantly higher in Han populations than in Europeans as a result of positive selection, and this is indeed the case (Consortium C (2015).

Many genes have been replicated across a range of ethnic/ racial groups as risk factors for schizophrenia, suggesting that at least certain pathways for the disorder are ancient and arose prior to the first migrations of modern humans out of Africa. From a PATHOS-D perspective, the fact that no such replicated risk alleles have been found for MDD may suggest that the condition is more environmentally based than are conditions with more universally established genetic risk genes, but not in the way that this environmental primacy is usually understood. Instead, MDD may have no universal risk genes because pathogen pressures in local environments over the last 60000 years have been pre-eminent in determining which specific immune mechanisms were most adaptively linked to the generation of depressive symptoms in any given environment. If it turns out that the association between depression and increased inflammation is a human universal (not universal in terms of all depressed individuals showing increased inflammation, but rather that groups of depressed individuals demonstrate increased inflammation across all ethnicities/cultures), then the clear prediction of PATHOS-D would be that alleles that confer depression risk in one population but not another should either (1) increase inflammatory signaling more in the population in which they confer risk; or (2) more powerfully increase the prevalence/ severity of depressive symptoms in response to any given degree of inflammatory activity in the population in which they confer risk.

Similarly, because present-day human societies/cultural groups have historically experienced widely different degrees of exposure to bacterial and viral pandemics that exerted extreme selective pressure (Fincher et al, 2008), PATHOS-D predicts that the types of immunity that best cope with these different types of pathogens should have different relationships with depression across human cultures. So, for example, because interferon signaling is especially essential for host defense against viruses, a PATHOS-D perspective would predict that individuals from cultures with higher rates of historical exposure to lethal viral pandemics should respond to treatment with IFN- $\alpha$ with increased rates of depression development, if indeed depressive symptoms aid in pathogen defense. Were it possible to assess, this effect should be largest in hunter-gatherer populations that have evolved in the types of low population density environments that work against widespread viral infections. In such populations, viruses provided little positive selection pressure that would link antiviral defenses with depression, whereas such populations would have benefitted from optimal protection against environmental pathogens (eg, protozoa, bacteria, and fungi) that would have increased mortality under these conditions. Were such a population available, the prediction is that they would show enhanced depressive symptoms in response to a bacterial stimulant such as endotoxin, while showing a muted depressive response to IFN- $\alpha$. Alas, given the escalating loss of isolated indigenous cultures, the time for such a definitive study may have passed.

Adaptive introgression provides another fascinating example of why pathogen-host defense processes may ensure that no universal genes for MDD will ever be found. Research over the last several years indicates that $\sim 2 \%$ of the DNA of non-African humans derives from multiple bouts of interbreeding with Neanderthals, with current Melanesian populations also showing a Denisovan genetic inheritance from ancestral interbreeding with that group of now-extinct archaic humans (Vernot et al, 2016). In general, the results of this interbreeding were deleterious, as attested to by multiple 'desert' regions of human DNA depleted of archaic genetic material. Against this backdrop, it is striking that other Neanderthal and Denisovan sequences appear to have undergone positive selection. From a PATHOS-D perspective it is even more striking that these archaic alleles are associated with both immune function and with an increased risk of depression (Mendez et al, 2012; Segurel and Quintana-Murci, 2014; Simonti et al, 2016). Although it does not yet appear that the same Neanderthal allelic variants code for both immunity and mood, anyone concerned with adaptive explanations for MDD cannot help but be struck by this association, especially given that negative selection appears to have removed archaic human DNA from areas of the genome involved with other aspects of CNS morphology and function. Researchers tend to assume that retained archaic immune alleles provided an adaptive benefit for coping with novel Eurasian pathogens; PATHOS-D would suggest that their proclivity to induce depression provided additional advantages in our endless struggles with microbes and parasites.

\section{UNEXPLAINED EPIDEMIOLOGICAL FEATURES OF MDD SUCH AS THOSE RELATED TO SEX SHOULD HAVE PROVIDED PROTECTION FROM INFECTIOUS MORTALITY IN HIGH-PATHOGEN ENVIRONMENTS}

Here we consider ways in which PATHOS-D might provide adaptive explanations (as opposed to mere proximal/ mechanistic explanations) for three epidemiological features of MDD that are striking characteristics of the disorder and relate directly to sex: (1) the 2:1 female preponderance of the disorder; (2) the impact of age and sex on the disorder's phenotypic presentation; and (3) the significant risk of the postpartum period for MDD development.

\section{Why is Female Sex a Risk for MDD?}

Females are approximately twice as likely as males to suffer from MDD (Seedat et al, 2009), with this imbalance being most pronounced during the reproductive years, exactly 
when the manifold negative social and biological effects of depression would be expected to impact evolutionary fitness most adversely (Fiske et al, 2009). While many answers for the female preponderance of depression have been proposed over the years (eg, females are more sensitive than males to the social environment), none have successfully identified an adaptive advantage that would outweigh the costs of female depression to survival and reproduction. In contrast, PATHOS-D suggests a testable explanation for why depression is so common in females of reproductive age. Females are more likely to develop depression during the reproductive years because across evolutionary time depressive symptoms-having evolved out of sickness-promoted behaviors that decreased the risk of pathogen exposure and provided increased protection from pathogens for any given level of inflammatory activation once an infection had occurred (eg, by increasing energy available to immune processes by inducing conservation-withdrawal behavior, maintaining elevated body temperature, and so on). Said differently, by inducing social and biological behaviors that promoted host defense against pathogens, depressive symptoms allowed females of reproductive age to 'get by' with less inflammation. The unique importance of this for reproductive success in females is highlighted by the fact that inflammation reduces fertility, impairs lactation and directs metabolic resources away from the multiple energetically-costly aspects of female biology that were required for successful reproduction in ancestral environments (Van Bodegom et al, 2007; Schaller, 2011; Kobayashi et al, 2013). Interestingly MDD has also been associated with reduced fertility (Williams et al, 2007; Nillni et al, 2016). PATHOS-D theory predicts that this association should less prominent in females who have effectively 'replaced' inflammation with depression-based behavioral pathogen avoidance in the absence of elevated levels of inflammatory biomarkers.

Although most implications of this idea remain to be tested, some data support the first prediction of this hypothesis, which is that females should develop increased levels of depression for any given amount of inflammatory exposure. Indeed, when compared with men, females respond to an injection of lipopolysaccharide (LPS) with an increase in depression and feelings of social isolation, both of which are correlated with amount of cytokine response to the LPS in females, but not males (Moieni et al, 2015b). Similarly, females are more likely than males to develop depression in response to chronic inflammatory stimulation resulting from treatment with the cytokine IFN- $\alpha$ (Udina et al, 2012). Finally, given the pre-eminent role of psychosocial stress as an environmental risk factor for MDD, as well as evidence that hyperthermia enhances host defense, it is intriguing that reproductive aged females appear to be most vulnerable to developing psychogenic fever (Kaneda et al, 2009). However, these findings need to be balanced against results from a small recent study indicating that females mounted an enhanced proinflammatory cytokine response to low-dose endotoxin when compared with men, while showing no difference in inflammation-induced mood or anxiety symptoms-a pattern of findings opposite to this PATHOS-D prediction (Engler et al, 2016). If confirmed in larger studies, these findings might support an alternative immune-based mechanism for the female/male preponderance of depression and anxiety, specifically that females respond to immune challenges with greater immune activation which subsequently increases the risk for depression/anxiety.

\section{Why is the Depressive Phenotype Affected by Sex and Age?}

MDD is most commonly characterized by impaired sleep and reduced appetite (Smith et al, 2008), but a significant minority of depressed individuals manifest hypersomnia and hyperphagia instead (Thase, 2009). These symptoms are most frequent in females between adolescence and middleage (Carter et al, 2000; Posternak and Zimmerman, 2001; Matza et al, 2003; Blanco et al, 2012). How might PATHOS$\mathrm{D}$ theory seek to account for the existence of these reversed neurovegative symptoms, as well as their age and sex distribution? A first step is to establish that cytokine pathways known to be activated by infection are capable of producing both hypersomnia and hyperphagia. Hypersomnia has been recognized for years as a primary behavioral manifestation of proinflammatory cytokines (Krueger and Majde, 1994; Krueger and Toth, 1994; Krueger and Majde, 2003; Opp, 2004, 2009), and studies in healthy adolescents and adults indicate that chronically increased sleep is associated with increased saliva and blood concentrations of IL-6 and CRP (El-Sheikh et al, 2007; Patel et al, 2009; Prather et al, 2015). In terms of feeding behavior, animal models demonstrate that inflammation promotes carbohydrate preference (Aubert et al, 1995), such as is typical in depressive hyperphagia. Less well known are data that highfat diets induce leptin and insulin resistance, as well as obesity, dependent upon activation of inflammatory mediators in the hypothalamus (Zhang et al, 2008; Kleinridders et al, 2009). Conversely, blocking hypothalamic inflammation prevents obesity and other stigmata of the metabolic syndrome, even in the context of high-fat consumption (Zhang et al, 2008; Milanski et al, 2009; Posey et al, 2009). In rodents, exposure to either TNF or IL-6 in utero results in adulthood obesity (Dahlgren et al, 2001), again suggesting that cytokines can induce hyperphagia/weight gain under certain circumstances. Although we know of no data showing that females are more likely than males to respond to inflammatory signaling with hyperphagia, female rodents have less anorexia than males in response to influenza infection (Avitsur et al, 2010).

Because the presence of widespread obesity is recent, the question arises as to whether more ancient signals for inflammatory activation might also promote hyperphagia, instead of anorexia. We know of no data that directly address this issue in terms of infection, but note that certain adenoviruses have been associated with weight gain 
(Atkinson, 2008; Mitra and Clarke, 2010). In terms of psychosocial factors, preclinical studies suggest that stressors associated with a high degree of wounding-such as chronic social defeat-induce hypothalamic resistance to leptin (Kleinridders et al, 2009; Chuang et al, 2010), consistent with their known ability to activate inflammatory pathways (Avitsur et al, 2005; Bailey et al, 2007, 2009; Powell et al, 2010). As in depression, where hyperphagia and weight gain are associated with disease chronicity (Posternak and Zimmerman, 2001), chronic social defeat leads initially to weight loss but to weight gain over time (Chuang et al, 2010). Given the role of leptin resistance in hyperphagia, it is intriguing that increased peripheral leptin levels (consistent with leptin resistance) have been observed more consistently in females than in males with MDD (Rubin et al, 2002; Yang et al, 2007; Pasco et al, 2008; Zeman et al, 2009; Cizza et al, 2010), and are more common in atypical than non-atypical depression (Gecici et al, 2005).

Why might younger individuals in general, and females in particular, be more likely to develop depressive conditions characterized by hypersomnia and hyperphagia? From a PATHOS-D perspective, the simplest answer may be: because they can. In hunter-gatherer societies youth and females are frequently more protected from predation and to have food supplied to them by others (Kaplan and Gurven, 2005), raising the possibility that in ancestral environments these individuals enjoyed sufficient security to partake of the recuperative effects of sleep and to eat without having to expend energy searching for food.

Given evidence that anorexia may confer anti-pathogen effects (Raison and Miller, 2012), might similar benefits accrue to hyperphagia, especially in youth and females, under at least some evolutionarily relevant situations? Although admittedly speculative, several lines of evidence suggest that by promoting hypothalamic resistance to leptin, genes associated with increased inflammatory signaling might enhance host defense by driving ongoing leptin production despite malnutrition in conditions of food scarcity. This increased leptin production would both augment the drive to seek and consume food and would lower the set point at which food consumption initiated the types of inflammatory responses that are all too common in the obese, but that appear to be life-saving in the face of an infection such as tuberculosis, that was (and is) most lethal for females of reproductive age and for which low body weight and reduced leptin are deadly (van Crevel et al, 2002; Wieland et al, 2005; Buyukoglan et al, 2007; Leung et al, 2007; Pednekar et al, 2008; Roth, 2009).

Depression and anxiety are highly comorbid, and in both animals and humans, activation of the inflammatory response produces both types of symptoms. In a previous publication, we devoted significant space to providing a PATHOS-D perspective on why inflammation produces changes in brain function that subserve not just conservation-withdrawal symptoms likely to aid in defense against pathogens, but that also have been associated with hypervigilance symptoms (eg, anxiety/agitation, insomnia, anger/irritability (Association AP, 2013)) that across human evolution would have presumably siphoned metabolic resources away from the life-or-death task of immune protection (Raison and Miller, 2012). We suggested that sickness behavior - while of benefit for surviving infectioncarries its own survival and reproduction costs as a result of increased risk for predation and reduced ability to care for one's young, as well as potential loss of status in a social species and/or loss of breeding territory (Miller and Cohen, 2005), all of which were relevant to humans in the EEA. Given these competing challenges to survival and reproduction, evolutionary logic may have dictated that inflammatory processes-especially when chronic-might have promoted hypervigilant behavior, which, while shunting energy away from fighting infection, would nonetheless have served adaptive purposes by protecting against environmental dangers engendered by sickness.

Given that human females and youth likely received more protection in the EEA than did adult males (who therefore on average would have more to lose from sickness behavior), a clear prediction from PATHOS-D is that males should respond to immune challenges/inflammatory activation with an increased ratio of hypervigilant to conservationwithdrawal symptoms, as well as an increase in cytokine effects on brain areas such as the dorsal anterior cingulate that subserve hypervigilance when compared with cytokine effects on areas such as the ventral striatum, which have been linked to inflammatory effects on anhedonia (Felger et al, 2015), which would be expected to promote social withdrawal. Available data provide mixed support for this hypothesis. On the one hand. a recent study found no difference between males and females in the severity of anxiety symptoms induced by low-dose endotoxin (Engler et al, 2016). On the other hand, a recent large cohort study reported that peripheral inflammatory biomarkers were more strongly associated with anxiety symptoms and anxiety disorders in males than in females (Duivis et al, 2013, Vogelzangs et al, 2013). More definitive confirmation or refutation of the possibility that males respond to inflammation with increased hypervigilance await studies specifically designed to assess the modulating effect of sex on the impact of cytokines on hypervigilant-specific behaviors and on neural pathways known to mediate this type of behavior.

\section{Why is The Postpartum Period a Risk Factor for MDD?}

Given significant evidence that maternal depression in the postpartum period is associated with numerous short- and long-term adverse consequences for the affected offspring (Ghodsian et al, 1984; Stein et al, 1991; Beardslee et al, 1998; Beck, 1999; Halligan et al, 2007; Kersten-Alvarez et al, 2012), the question of why the condition is so common is especially pressing. As with all evolutionary considerations, the first question to consider is whether risk genes that promote postpartum depression (PPD) confer an adaptive benefit, at least in part, via benefits resulting from the 
condition itself or whether PPD is pleiotropically linked to non-related effects of these genes that benefitted survival and/or reproduction across evolution in ways that outweighed the cost of PPD. From a PATHOS-D perspective, the question might be framed by asking whether PPD enhanced maternal survival and/or reproduction via an overall net benefit in pathogen-host defense.

In terms of maternal survival, PPD would be expected to serve the same pathogen defense purposes as MDD in general. However, what about the survival of the newborn, which reflects a significant investment on the mother's part in her long-term reproductive success? Might maternal depression contribute to the child's pathogen-host defense prospects? An interesting twist on this theme might be provided by Parental Investment Theory, which postulates that parents reduce their care for, and involvement with, offspring when the costs of such care and involvement outweigh the benefits (Trivers, 1972). Building on this theory, it has been argued that PPD is an evolved mechanism that aids mothers in disengaging from infants with a low chance of surviving (Hagen, 1999; Bottino et al, 2012). Because infection was the primary cause of infant mortality across human evolution, one might predict that PPD would be more likely to develop in response to giving birth to an unhealthy infant, and data from hunter-horticulturalists in the Amazon basin are consistent with this prediction (Hagen and Barrett, 2007). Under this scenario, PPD, rather than helping the infant survive pathogen challenge, would actually serve as a 'warning signal' to the mother that the infant's likelihood of surviving postnatal pathogen exposure was not high enough to warrant significant resource investments.

Although consistent with a PATHOS-D focus on the primacy of pathogen-host interactions in selecting for depression-promoting genetic variants, the notion that PPD functions as a type of immunological abandonment strategy goes against the general tenor of the theory, which sees the link between depression and immunity as providing overall advantages in the face of infectious morbidity and mortality, whatever their costs in other domains. Whether PPD is associated with behavioral or immune changes that might actually help infant survival-especially in conditions such as high environmental pathogen exposure, reduced metabolic resources or increased infant vulnerability to infection-is a question that to our knowledge has never been examined. Certainly it is possible that PPD-induced maternal withdrawal might have decreased the risk of infant infection in circumstances when the maternal depression resulted from pathogen-induced cytokine activation. It is also intriguing to speculate that PPD might influence the composition of breast milk in ways that might aid nursing infants in avoiding or surviving infection. Intriguingly, a Japanese study found PPD to be associated with increased breast milk concentrations of the cytokine transforming growth factor (TGF)- $\beta 2$. TGF- $\beta 2$ has complex pro- and antiinflammatory effects (Kondo et al, 2011), but in the context of the newborn immune system, it has been shown to have a key role in establishing the mucosal immune response, including production of secretory immunoglobulin A (Ogawa et al, 2004; Oddy and Rosales, 2010). Also of potential relevance, reduced levels of TGF- $\beta$ have been associated with increased symptom severity in children infected with Plasmodium falciparum (Chaiyaroj et al, 2004; Rovira-Vallbona et al, 2012), suggesting that the provision of increased TGF- $\beta 2$ in breast milk from depressed mothers might confer some protection against malaria, which has been a primary source of pathogen-induced mortality across human evolution. Importantly, TGF- $\beta$ and other immune factors in breast milk remain biologically active after passage through the infant stomach as a result of its higher $\mathrm{pH}$ (Hennet and Borsig, 2016).

\section{CONCLUSION}

In essence, PATHOS-D does nothing more than attempt to instantiate and provide specifics to the observation from the quote that started this article, that 'the only...compensating fitness benefit that has been documented for major human genetic diseases is resistance to infection' (Cochran et al, 2000). We have argued that depression and its relationship with inflammation and in particular the acute phase response is yet another example of this evolutionary reality, providing insights into the puzzling lack of consistency of risk alleles across populations as well as the epidemiology of the disorder including its risk factors in ancient and modern times and its age of onset and female preponderance.

\section{FUNDING AND DISCLOSURE}

Funding for this study was provided for CLR by Mary Sue and Mike Shannon, the Usona Institute and the University of Wisconsin-Madison and for AHM by R03MH100273; R01MH087604; Supported In part by the National Center for Advancing Translational Sciences of the National Institutes of Health under Award number UL1TR000454. The content is solely the responsibility of the authors and does not necessarily represent the official views of the National Institutes of Health. Study funders had no role in the design and conduct of the study; collection, management, analysis and interpretation of the data; preparation, review, or approval of the manuscript; and decision to submit the manuscript for publication. Dr Raison serves on the Scientific Advisory Board for Usona Institute. Dr Miller reports no conflicts of interest.

\section{REFERENCES}

Abe-Higuchi N, Uchida S, Yamagata H, Higuchi F, Hobara T, Hara K et al (2016). Hippocampal sirtuin 1 signaling mediates depression-like behavior. Biol Psychiatry e-pub ahead of print 30 January 2016; doi:10.1016/j.biopsych.2016.01.009. Akimova T, Xiao H, Liu Y, Bhatti TR, Jiao J, Eruslanov E et al (2014). Targeting sirtuin-1 alleviates experimental autoimmune colitis by induction of Foxp3+ T-regulatory cells. Mucosal Immunol 7: 1209-1220.

Anders S, Tanaka M, Kinney DK (2013). Depression as an evolutionary strategy for defense against infection. Brain Behav Immun 31: 9-22. 
Andersson NW, Goodwin RD, Okkels N, Gustafsson LN, Taha F, Cole SW et al (2016). Depression and the risk of severe infections: prospective analyses on a nationwide representative sample. Int J Epidemiol 45: 131-139.

Annamanedi M, Kalle AM (2014). Celecoxib sensitizes Staphylococcus aureus to antibiotics in macrophages by modulating SIRT1. PLOS ONE 9: e99285.

Ansari A, Talat N, Jamil B, Hasan Z, Razzaki T, Dawood G et al (2009). Cytokine gene polymorphisms across tuberculosis clinical spectrum in Pakistani patients. PLOS ONE 4: e4778.

Armelagos GJ, Brown PJ, Turner B (2005). Evolutionary, historical and political economic perspectives on health and disease. Soc Sci Med 61: 755-765.

Aschbacher K, Epel E, Wolkowitz OM, Prather AA, Puterman E, Dhabhar FS (2012). Maintenance of a positive outlook during acute stress protects against proinflammatory reactivity and future depressive symptoms. Brain Behav Immun 26: 346-352.

Association AP (2013). Diagnostic and statistical manual of mental disorders, 5th edn. DSM-5 American Psychiatric Association: Arlington, VA.

Atkinson RL (2008). Could viruses contribute to the worldwide epidemic of obesity? Int J Pediatr Obes 3(Suppl 1): 37-43.

Aubert A, Goodall G, Dantzer R (1995). Compared effects of cold ambient temperature and cytokines on macronutrient intake in rats. Physiol Behav 57: 869-873.

Avitsur R, Kavelaars A, Heinen C, Sheridan JF (2005). Social stress and the regulation of tumor necrosis factor-alpha secretion. Brain Behav Immun 19: 311-317.

Avitsur R, Mays JW, Sheridan JF (2011). Sex differences in the response to influenza virus infection: modulation by stress. Horm Behav 59: 257-264.

Avitsur R, Yirmiya R (1999). The immunobiology of sexual behavior: gender differences in the suppression of sexual activity during illness. Pharmacol Biochem Behav 64: 787-796.

Bailey MT, Engler H, Powell ND, Padgett DA, Sheridan JF (2007). Repeated social defeat increases the bactericidal activity of splenic macrophages through a Tolllike receptor-dependent pathway. Am J Physiol Regul Integr Comp Physiol 293: R1180-R1190.

Bailey MT, Kinsey SG, Padgett DA, Sheridan JF, Leblebicioglu B (2009). Social stress enhances IL-1beta and TNF-alpha production by Porphyromonas gingivalis lipopolysaccharide-stimulated CD11b+ cells. Physiol Behav 98: 351-358.

Beadling C, Slifka MK (2004). How do viral infections predispose patients to bacterial infections? Curr Opin Infect Dis 17: 185-191.

Beardslee WR, Versage EM, Gladstone TR (1998). Children of affectively ill parents: a review of the past 10 years. J Am Acad Child Adolesc Psychiatry 37: 1134-1141.

Beck CT (1999). Maternal depression and child behaviour problems: a metaanalysis. J Adv Nurs 29: 623-629.

Beekman M, Nederstigt C, Suchiman HE, Kremer D, van der Breggen R, Lakenberg N et al (2010). Genome-wide association study (GWAS)-identified disease risk alleles do not compromise human longevity. Proc Natl Acad Sci USA 107: 18046-18049

Benros ME, Waltoft BL, Nordentoft M, Ostergaard SD, Eaton WW, Krogh J et al (2013). Autoimmune diseases and severe infections as risk factors for mood disorders: a nationwide study. JAMA Psychiatry 70: 812-820.

Berg L, Rostila M, Hjern A (2016). Parental death during childhood and depression in young adults - a national cohort study. J Child Psychol Psychiatry. 57: 1092-1098.

Bermejo-Martin JF, Martin-Loeches I, Rello J, Anton A, Almansa R, Xu L et al (2010). Host adaptive immunity deficiency in severe pandemic influenza. Crit Care 14: R167.

Berry DS, Miller KM (2001). When boy meets girl: attractiven4ess and the five-factor model in opposite-sex interactions. J Res Personality 35: 62-77.

Bierhaus A, Wolf J, Andrassy M, Rohleder N, Humpert PM, Petrov D et al (2003). A mechanism converting psychosocial stress into mononuclear cell activation. Proc Natl Acad Sci USA 100: 1920-1925.

Bigos KL, Mattay VS, Callicott JH, Straub RE, Vakkalanka R, Kolachana B et al (2010). Genetic variation in CACNA1C affects brain circuitries related to mental illness. Arch Gen Psychiatry 67: 939-945.

Black C, Miller BJ (2015). Meta-analysis of cytokines and chemokines in suicidality: distinguishing suicidal versus nonsuicidal patients. Biol Psychiatry 78: 28-37.

Blanco C, Vesga-Lopez O, Stewart JW, Liu SM, Grant BF, Hasin DS (2012). Epidemiology of major depression with atypical features: results from the National Epidemiologic Survey on Alcohol and Related Conditions (NESARC). J Clin Psychiatry 73: 224-232.

Blume J, Douglas SD, Evans DL (2011). Immune suppression and immune activation in depression. Brain Behav Immun 25: 221-229.

Bornand D, Toovey S, Jick SS, Meier CR (2016). The risk of new onset depression in association with influenza - A population-based observational study. Brain Behav Immun 53: 131-137.
Bottino MN, Nadanovsky P, Moraes CL, Reichenheim ME, Lobato G (2012). Reappraising the relationship between maternal age and postpartum depression according to the evolutionary theory: Empirical evidence from a survey in primary health services. J Affect Disord 142: 219-224.

Buyukoglan H, Gulmez I, Kelestimur F, Kart L, Oymak FS, Demir R et al (2007). Leptin levels in various manifestations of pulmonary tuberculosis. Mediators Inflamm 2007: 64859.

Calabrese JR, Skwerer RG, Barna B, Gulledge AD, Valenzuela R, Butkus A et al (1986). Depression, immunocompetence, and prostaglandins of the $E$ series. Psychiatry Res 17: 41-47.

Capuron L, Fornwalt FB, Knight BT, Harvey PD, Ninan PT, Miller AH (2009). Does cytokine-induced depression differ from idiopathic major depression in medically healthy individuals? J Affect Disord 119: 181-185.

Capuron L, Gumnick JF, Musselman DL, Lawson DH, Reemsnyder A, Nemeroff CB et al (2002). Neurobehavioral effects of interferon-alpha in cancer patients: phenomenology and paroxetine responsiveness of symptom dimensions. Neuropsychopharmacology 26: 643-652.

Capuron L, Neurauter G, Musselman DL, Lawson DH, Nemeroff CB, Fuchs D et al (2003a). Interferon-alpha-induced changes in tryptophan metabolism. relationship to depression and paroxetine treatment. Biol Psychiatry 54: 906-914.

Capuron L, Pagnoni G, Demetrashvili M, Woolwine BJ, Nemeroff CB, Berns GS et al (2005). Anterior cingulate activation and error processing during interferon-alpha treatment. Biol Psychiatry 58: 190-196.

Capuron L, Pagnoni G, Demetrashvili MF, Lawson DH, Fornwalt FB, Woolwine BJ et al (2007). Basal ganglia hypermetabolism and symptoms of fatigue during interferon-alpha therapy. Neuropsychopharmacology 32: 2384-2392.

Capuron L, Raison CL, Musselman DL, Lawson DH, Nemeroff CB, Miller AH (2003b). Association of exaggerated HPA axis response to the initial injection of interferon-alpha with development of depression during interferon-alpha therapy. Am J Psychiatry 160: 1342-1345.

Cardoso CC, Pereira AC, Brito-de-Souza VN, Dias-Baptista IM, Maniero VC, Venturini $J$ et al (2010). IFNG +874 T>A single nucleotide polymorphism is associated with leprosy among Brazilians. Hum Genet 128: 481-490.

Carpenter LL, Gawuga CE, Tyrka AR, Lee JK, Anderson GM, Price LH (2010). Association between plasma IL-6 response to acute stress and early-life adversity in healthy adults. Neuropsychopharmacology 35: 2617-2623.

Carter JD, Joyce PR, Mulder RT, Luty SE, McKenzie J (2000). Gender differences in the presentation of depressed outpatients: a comparison of descriptive variables. J Affect Disord 61: 59-67.

Chaiyaroj SC, Rutta AS, Muenthaisong K, Watkins P, Na Ubol M, Looareesuwan S (2004). Reduced levels of transforming growth factor-beta1, interleukin-12 and increased migration inhibitory factor are associated with severe malaria. Acta Trop 89: 319-327.

Chen J, Shen H, Chen C, Wang W, Yu S, Zhao M et al (2009). The effect of psychological stress on iron absorption in rats. BMC Gastroenterol 9: 83.

Chong WP, Ip WK, Tso GH, Ng MW, Wong WH, Law HK et al (2006). The interferon gamma gene polymorphism $+874 \mathrm{~A} T$ is associated with severe acute respiratory syndrome. BMC Infect Dis 6: 82 .

Chuang JC, Krishnan V, Yu HG, Mason B, Cui H, Wilkinson MB et al (2010). A beta3-adrenergic-leptin-melanocortin circuit regulates behavioral and metabolic changes induced by chronic stress. Biol Psychiatry 67: 1075-1082.

Cizza G, Nguyen VT, Eskandari F, Duan Z, Wright EC, Reynolds JC et al (2010). Low 24- hour adiponectin and high nocturnal leptin concentrations in a case-control study of community-dwelling premenopausal women with major depressive disorder: the Premenopausal, Osteopenia/Osteoporosis, Women, Alendronate, Depression (POWER) study. J Clin Psychiatry 71: 1079-1087.

Clark J, Vagenas P, Panesar M, Cope AP (2005). What does tumour necrosis factor excess do to the immune system long term? Ann Rheum Dis 64(Suppl 4): iv70-iv76.

Cochran GM, Ewald PW, Cochran KD (2000). Infectious causation of disease: an evolutionary perspective. Perspect Biol Med 43: 406-448.

Cole SW (2006). The complexity of dynamic host networks. In: Complex Systems Science in Biomedicine. Deisboeck T. S., Kresh J. Y. eds. Springer: New York, NY.

Consortium C (2015). Sparse whole-genome sequencing identifies two loci for major depressive disorder. Nature 523: 588-591.

Constant A, Castera L, Dantzer R, Couzigou P, de Ledinghen V, Demotes-Mainard J et al (2005). Mood alterations during interferon-alfa therapy in patients with chronic hepatitis C: evidence for an overlap between manic/hypomanic and depressive symptoms. J Clin Psychiatry 66: 1050-1057.

Cope AP (2003). Exploring the reciprocal relationship between immunity and inflammation in chronic inflammatory arthritis. Rheumatology (Oxford) 42: 716-731.

Cope AP, Liblau RS, Yang XD, Congia M, Laudanna C, Schreiber RD et al (1997). Chronic tumor necrosis factor alters $T$ cell responses by attenuating $T$ cell receptor signaling. J Exp Med 185: 1573-1584. 
Corsini E, Vismara L, Lucchi L, Viviani B, Govoni S, Galli CL et al (2006). High interleukin-10 production is associated with low antibody response to influenza vaccination in the elderly. J Leukoc Biol 80: 376-382.

Cruess DG, Petitto JM, Leserman J, Douglas SD, Gettes DR, Ten Have TR et al (2003). Depression and HIV infection: impact on immune function and disease progression. CNS Spectr 8: 52-58.

Dahlgren J, Nilsson C, Jennische E, Ho HP, Eriksson E, Niklasson A et al (2001). Prenatal cytokine exposure results in obesity and gender-specific programming. Am J Physiol Endocrinol Metab 281: E326-E334.

Dantzer R (2006). Cytokine, sickness behavior, and depression. Neurol Clin 24: $441-460$.

Dantzer R, O'Connor JC, Freund GG, Johnson RW, Kelley KW (2008a). From inflammation to sickness and depression: when the immune system subjugates the brain. Nat Rev Neurosci 9: 46-56.

Dantzer R, O'Connor JC, Freund GG, Johnson RW, Kelley KW (2008b). From inflammation to sickness and depression: when the immune system subjugates the brain. Nat Rev Neurosci 9: 46-56.

Degre M, Glasgow LA (1968). Synergistic effect in viral-bacterial infection. I. Combined infection of the respiratory tract in mice with parainfluenza virus and Hemophilus influenza. J Infect Dis 118: 449-462.

Dhabhar FS (2009). Enhancing versus suppressive effects of stress on immune function: implications for immunoprotection and immunopathology. Neuroimmunomodulation 16: 300-317.

DiPietro LA (1995). Wound healing: the role of the macrophage and other immune cells. Shock 4: 233-240.

Doering LV, Martinez-Maza O, Vredevoe DL, Cowan MJ (2008). Relation of depression, natural killer cell function, and infections after coronary artery bypass in women. Eur J Cardiovasc Nurs 7: 52-58.

Dong-Newsom P, Powell ND, Bailey MT, Padgett DA, Sheridan JF (2010). Repeated social stress enhances the innate immune response to a primary HSV-1 infection in the cornea and trigeminal ganglia of Balb/c mice. Brain Behav Immun 24: 273-280.

Doran MF, Crowson CS, Pond GR, O'Fallon WM, Gabriel SE (2002). Frequency of infection in patients with rheumatoid arthritis compared with controls: a population-based study. Arthritis Rheum 46: 2287-2293.

Dowlati Y, Herrmann N, Swardfager W, Liu H, Sham L, Reim EK et al (2010). A metaanalysis of cytokines in major depression. Biol Psychiatry 67: 446-457.

Drenos F, Westendorp RG, Kirkwood TB (2006). Trade-off mediated effects on the genetics of human survival caused by increasingly benign living conditions. Biogerontology 7: 287-295.

Duivis HE, Vogelzangs N, Kupper N, de Jonge P, Penninx BW (2013). Differentia association of somatic and cognitive symptoms of depression and anxiety with inflammation: findings from the Netherlands Study of Depression and Anxiety (NESDA). Psychoneuroendocrinology 38: 1573-1585.

Eaton WW, Anthony JC, Gallo J, Cai G, Tien A, Romanoski A et al (1997). Natural history of Diagnostic Interview Schedule/DSM-IV major depression. The Baltimore Epidemiologic Catchment Area follow-up. Arch Gen Psychiatry 54: 993-999.

Eisenberger NI, Berkman ET, Inagaki TK, Rameson LT, Mashal NM, Irwin MR (2010a). Inflammation-induced anhedonia: endotoxin reduces ventral striatum responses to reward. Biol Psychiatry 68: 748-754.

Eisenberger NI, Inagaki TK, Mashal NM, Irwin MR (2010b). Inflammation and social experience: an inflammatory challenge induces feelings of social disconnection in addition to depressed mood. Brain Behav Immun 24: 558-563.

El-Sheikh M, Buckhalt JA, Granger DA, Erath SA, Acebo C (2007). The association between children's sleep disruption and salivary interleukin-6. J Sleep Res 16: 188-197.

Eleftheriadis T, Kartsios C, Yiannaki E, Antoniadi G, Kazila P, Pliakos K et al (2009). Decreased CD3+CD16+ natural killer-like T-cell percentage and zeta-chain expression accompany chronic inflammation in haemodialysis patients. Nephrology (Carlton) 14: 471-475.

Engel GL, Schmale AH (1972). Conservation-withdrawal: a primary regulatory process for organismic homeostasis. Ciba Found Symp 8: 57-75.

Engler H, Benson S, Wegner A, Spreitzer I, Schedlowski M, Elsenbruch S (2016). Men and women differ in inflammatory and neuroendocrine responses to endotoxin but not in the severity of sickness symptoms. Brain Behav Immun 52: 18-26.

Erk S, Meyer-Lindenberg A, Schnell K, Opitz von Boberfeld C, Esslinger C, Kirsch P et al (2010). Brain function in carriers of a genome-wide supported bipolar disorder variant. Arch Gen Psychiatry 67: 803-811.

Eshed V, Gopher A, Pinhasi R, Hershkovitz I (2010). Paleopathology and the origin of agriculture in the Levant. Am J Phys Anthropol 143: 121-133.

Evans DL, Ten Have TR, Douglas SD, Gettes DR, Morrison M, Chiappini MS et al (2002). Association of depression with viral load, CD8 T lymphocytes, and natural killer cells in women with HIV infection. Am J Psychiatry 159: 1752-1759.
Eyre HA, Air T, Pradhan A, Johnston J, Lavretsky H, Stuart MJ et al (2016). A metaanalysis of chemokines in major depression. Prog Neuropsychopharmacol Biol Psychiatry 68: 1-8.

Faulkner S, Smith A (2008). A longitudinal study of the relationship between psychological distress and recurrence of upper respiratory tract infections in chronic fatigue syndrome. $\mathrm{Br} J$ Health Psychol 13: 177-186.

Felger JC, Alagbe O, Pace TW, Woolwine BJ, Hu F, Raison CL et al (2011). Early activation of p38 mitogen activated protein kinase is associated with interferonalpha-induced depression and fatigue. Brain Behav Immun 25: 1094-1098.

Felger JC, Li L, Marvar PJ, Woolwine BJ, Harrison DG, Raison CL et al (2012). Tyrosine metabolism during interferon-alpha administration: Association with fatigue and CSF dopamine concentrations. Brain Behav Immun. 31: 153-160.

Felger JC, Li Z, Haroon E, Woolwine BJ, Jung MY, Hu X et al (2015). Inflammation is associated with decreased functional connectivity within corticostriatal reward circuitry in depression. Mol Psychiatry 21: 1358-1365.

Fernandez-Marcos PJ, Auwerx J (2011). Regulation of PGC-1alpha, a nodal regulator of mitochondrial biogenesis. Am J Clin Nutr 93: 884S-88890.

Fincher CL, Thornhill R, Murray DR, Schaller M (2008). Pathogen prevalence predicts human cross-cultural variability in individualism/collectivism. Proc Biol Sci $\mathbf{2 7 5}$ 1279-1285.

Fiske A, Wetherell JL, Gatz M (2009). Depression in older adults. Annu Rev Clin Psychol 5: 363-389.

Forte GI, Scola L, Misiano G, Milano S, Mansueto P, Vitale G et al (2009). Relevance of gamma interferon, tumor necrosis factor alpha, and interleukin-10 gene polymorphisms to susceptibility to Mediterranean spotted fever. Clin Vaccine Immunol 16: 811-815.

Fowler JH, Christakis NA (2008). Dynamic spread of happiness in a large social network: longitudinal analysis over 20 years in the Framingham Heart Study. Bmj 337: a2338.

Franzen PL, Buysse DJ, Rabinovitz M, Pollock BG, Lotrich FE (2010). Poor sleep quality predicts onset of either major depression or subsyndromal depression with irritability during interferon-alpha treatment. Psychiatry Res 177: 240-245.

Gallagher PM, Lowe G, Fitzgerald T, Bella A, Greene CM, McElvaney NG et al (2003). Association of IL-10 polymorphism with severity of illness in community acquired pneumonia. Thorax 58: 154-156.

Gao QJ, Liu DW, Zhang SY, Jia M, Wang LM, Wu LH et al (2009). Polymorphisms of some cytokines and chronic hepatitis B and C virus infection. World $J$ Gastroenterol 15: 5610-5619.

Gecici O, Kuloglu M, Atmaca M, Tezcan AE, Tunckol H, Emul HM et al (2005). High serum leptin levels in depressive disorders with atypical features. Psychiatry Clin Neurosci 59: 736-738.

Ghodsian M, Zajicek E, Wolkind S (1984). A longitudinal study of maternal depression and child behaviour problems. J Child Psychol Psychiatry 25: 91-109.

Gili M, Garcia-Toro M, Vives M, Armengol S, Garcia-Campayo J, Soriano JB et al (2010). Medical comorbidity in recurrent versus first-episode depressive patients. Acta Psychiatr Scand 123: 220-227.

Goldsmith DR, Haroon E, Woolwine BJ, Jung MY, Wommack EC, Harvey PD et al (2016a). Inflammatory markers are associated wtih decreased psychomotor speed in patients with major depressive disorder. Brain Behav Immun Epub 56: 281-288.

Goldsmith DR, Rapaport MH, Miller BJ (2016b). A meta-analysis of blood cytokine network alterations in psychiatric patients: comparisons between schizophrenia, bipolar disorder and depression. Mol Psychiatry; e-pub ahead of print 23 February 2016; doi: 10.1038/mp.2016.3.

Goldstein BI, Kemp DE, Soczynska JK, McIntyre RS (2009). Inflammation and the phenomenology, pathophysiology, comorbidity, and treatment of bipolar disorder: a systematic review of the literature. J Clin Psychiatry 70: 1078-1090.

Goshen I, Yirmiya R (2009). Interleukin-1 (IL-1): a central regulator of stress responses. Front Neuroendocrino/ 30: 30-45.

Gunaratne P, Lloyd AR, Vollmer-Conna U (2013). Mood disturbance after infection. Aust N Z J Psychiatry 47: 1152-1164.

Haapakoski R, Mathieu J, Ebmeier KP, Alenius H, Kivimaki M (2015). Cumulative meta-analysis of interleukins 6 and 1beta, tumour necrosis factor alpha and C-reactive protein in patients with major depressive disorder. Brain Behav Immun 49: 206-215.

Hagen EH (1999). The functions of postpartum depression. Evol Hum Behav 20: 325-359.

Hagen EH, Barrett HC (2007). Perinatal sadness among Shuar women: support for an evolutionary theory of psychic pain. Med Anthropol Q 21: 22-40.

Halligan SL, Murray L, Martins C, Cooper PJ (2007). Maternal depression and psychiatric outcomes in adolescent offspring: a 13-year longitudinal study. J Affect Disord 97: 145-154.

Hamrick N, Cohen S, Rodriguez MS (2002). Being popular can be healthy or unhealthy: stress, social network diversity, and incidence of upper respiratory infection. Health Psychol 21: 294-298. 
Hanff TC, Furst SJ, Minor TR (2010). Biochemical and anatomical substrates of depression and sickness behavior. Isr J Psychiatry Relat Sci 47: 64-71.

Hannestad J, DellaGioia N, Ortiz N, Pittman B, Bhagwagar Z (2011). Citalopram reduces endotoxin-induced fatigue. Brain Behav Immun 25: 256-259.

Harder J, Dressel S, Wittersheim M, Cordes J, Meyer-Hoffert U, Mrowietz U et al (2010). Enhanced expression and secretion of antimicrobial peptides in atopic dermatitis and after superficial skin injury. J Invest Dermatol 130: 1355-1364.

Harder J, Glaser R, Schroder JM (2007). The role and potential therapeutical applications of antimicrobial proteins in infectious and inflammatory diseases. Endocr Metab Immune Disord Drug Targets 7: 75-82.

Harder J, Schroder JM (2005). Psoriatic scales: a promising source for the isolation of human skin-derived antimicrobial proteins. J Leukoc Biol 77: 476-486.

Harrison NA, Brydon L, Walker C, Gray MA, Steptoe A, Critchley HD (2009a). Inflammation causes mood changes through alterations in subgenual cingulate activity and mesolimbic connectivity. Biol Psychiatry 66: 407-414.

Harrison NA, Brydon L, Walker C, Gray MA, Steptoe A, Dolan RJ et al (2009b). Neural origins of human sickness in interoceptive responses to inflammation. Biol Psychiatry 66: 415-422.

Hayashida S, Oka T, Mera T, Tsuji S (2010). Repeated social defeat stress induces chronic hyperthermia in rats. Physiol Behav 101: 124-131.

Hennet T, Borsig L (2016). Breastfed at tiffany's. Trends Biochem Sci. 41: 508-518.

Herbert TB, Cohen S (1993a). Depression and immunity: a meta-analytic review. Psychol Bull 113: 472-486

Herbert TB, Cohen S (1993b). Stress and immunity in humans: a metaanalytic review. Psychosom Med 55: 364-379.

Herbert TB, Cohen S (1993c). Stress and immunity in humans: a metaanalytic review. Psychosom Med 55: 364-379.

Hohler T, Reuss E, Freitag CM, Schneider PM (2005). A functional polymorphism in the IL-10 promoter influences the response after vaccination with $\mathrm{HBsAg}$ and hepatitis A. Hepatology 42: 72-76.

Howren MB, Lamkin DM, Suls J (2009). Associations of depression with C-reactive protein, IL-1, and IL-6: a meta-analysis. Psychosom Med 71: 171-186.

Hung YY, Huang KW, Kang HY, Huang GY, Huang TL (2015). Antidepressants normalize elevated Toll-like receptor profile in major depressive disorder. Psychopharmacology (Berl) 233: 1707-1714.

Hung YY, Kang HY, Huang KW, Huang TL (2014). Association between toll-like receptors expression and major depressive disorder. Psychiatry Res 220: 283-286.

Inagaki TK, Muscatell KA, Irwin MR, Moieni M, Dutcher JM, Jevtic I et al (2015). The role of the ventral striatum in inflammatory-induced approach toward support figures. Brain Behav Immun 44: 247-252.

Irwin MR, Cole SW (2011). Reciprocal regulation of the neural and innate immune systems. Nat Rev Immunol 11: 625-632.

Jakab GJ, Dick EC (1973). Synergistic effect in viral-bacterial infection: combined infection of the murine respiratory tract with Sendai virus and Pasteurella pneumotropica. Infect Immun 8: 762-768.

Jimenez-Fernandez S, Gurpegui M, Diaz-Atienza F, Perez-Costillas L, Gerstenberg M, Correll CU (2015). Oxidative stress and antioxidant parameters in patients with major depressive disorder compared to healthy controls before and after antidepressant treatment: results from a meta-analysis. J Clin Psychiatry 76: 1658-1667.

Joachim RA, Handjiski B, Blois SM, Hagen E, Paus R, Arck PC (2008). Stressinduced neurogenic inflammation in murine skin skews dendritic cells towards maturation and migration: key role of intercellular adhesion molecule-1/leukocyte function-associated antigen interactions. Am J Pathol 173: 1379-1388.

Jokela M, Virtanen M, Batty GD, Kivimaki M (2016). Inflammation and specific symptoms of depression. JAMA Psychiatry 73: 87-88.

Jones WT, Menna JH, Wennerstrom DE (1983). Lethal synergism induced in mice by influenza type A virus and type la group B streptococci. Infect Immun 41: $618-623$

Joosten KF, de Kleijn ED, Westerterp M, de Hoog M, Eijck FC, WCJ Hop et al (2000). Endocrine and metabolic responses in children with meningoccocal sepsis: striking differences between survivors and nonsurvivors. J Clin Endocrinol Metab 85: 3746-3753.

Kaneda Y, Tsuji S, Oka T (2009). Age distribution and gender differences in psychogenic fever patients. Biopsychosoc Med 3: 6 .

Kaplan H, Gurven M (2005). The natural history of human food sharing and cooperation: a review and a new multi-individual approach to the negotiation of norms. In: Moral Sentiments and Material Interests: On the Foundations of Cooperation in Economic Life, Gintis H. et al eds. MIT Press: Boston, MA.

Kataoka N, Hioki H, Kaneko T, Nakamura K (2014). Psychological stress activates a dorsomedial hypothalamus-medullary raphe circuit driving brown adipose tissue thermogenesis and hyperthermia. Cell Metab 20: 346-358.

Keri S, Szabo C, Kelemen O (2014). Expression of Toll-Like Receptors in peripheral blood mononuclear cells and response to cognitive-behavioral therapy in major depressive disorder. Brain Behav Immun 40: 235-243.
Kersten-Alvarez LE, Hosman CM, Riksen-Walraven JM, van Doesum KT, Smeekens S, Hoefnagels C (2012). Early school outcomes for children of postpartum depressed mothers: comparison with a community sample. Child Psychiatry Hum Dev 43: 201-218.

Kessler RC, Birnbaum H, Bromet E, Hwang I, Sampson N, Shahly V (2010). Age differences in major depression: results from the National Comorbidity Survey Replication (NCS-R). Psychol Med 40: 225-237.

Kinney DK, Tanaka M (2009). An evolutionary hypothesis of depression and its symptoms, adaptive value, and risk factors. J Nerv Ment Dis 197: 561-567.

Kleinridders A, Schenten D, Konner AC, Belgardt BF, Mauer J, Okamura T et al (2009). MyD88 signaling in the CNS is required for development of fatty acidinduced leptin resistance and diet-induced obesity. Cell Metab 10: 249-259.

Kluger MJ, Rothenburg BA (1979). Fever and reduced iron: their interaction as a host defense response to bacterial infection. Science 203: 374-376.

Kobayashi K, Uejyo T, Oyama S, Rahman MM, Kumura H (2013). Histological analysis of mammary gland remodeling caused by lipopolysaccharide in lactating mice. Cell Tissue Res 354: 495-506.

Kondo N, Suda Y, Nakao A, Oh-Oka K, Suzuki K, Ishimaru K et al (2011). Maternal psychosocial factors determining the concentrations of transforming growth factor-beta in breast milk. Pediatr Allergy Immunol 22: 853-861.

Krueger JM, Majde JA (1994). Microbial products and cytokines in sleep and fever regulation. Crit Rev Immunol 14: 355-379.

Krueger JM, Majde JA (2003). Humoral links between sleep and the immune system: research issues. Ann N Y Acad Sci 992: 9-20.

Krueger JM, Toth LA (1994). Cytokines as regulators of sleep. Ann N Y Acad Sci 739: 299-310.

Kuningas M, May L, Tamm R, van Bodegom D, van den Biggelaar AH, Meij JJ et al (2009). Selection for genetic variation inducing pro-inflammatory responses under adverse environmental conditions in a Ghanaian population. PLOS ONE 4: e7795.

Larcombe LA, Orr PH, Lodge AM, Brown JS, Dembinski IJ, Milligan LC et al (2008). Functional gene polymorphisms in canadian aboriginal populations with high rates of tuberculosis. J Infect Dis 198: 1175-1179.

LeGrand EK, Alcock J (2012). Turning up the heat: immune brinksmanship in the acute-phase response. Q Rev Biol 87: 3-18.

Leserman J (2008). Role of depression, stress, and trauma in HIV disease progression. Psychosom Med 70: 539-545.

Leung CC, Lam TH, Chan WM, Yew WW, Ho KS, Leung G et al (2007). Lower risk of tuberculosis in obesity. Arch Intern Med 167: 1297-1304.

Leutscher PD, Lagging M, Buhl MR, Pedersen C, Norkrans G, Langeland N et al (2010). Evaluation of depression as a risk factor for treatment failure in chronic hepatitis C. Hepatology 52: 430-435.

Levine J, Barak Y, Chengappa KN, Rapoport A, Rebey M, Barak V (1999). Cerebrospinal cytokine levels in patients with acute depression. Neuropsychobiology 40: 171-176.

Li J, Cowden LG, King JD, Briles DA, Schroeder HW Jr, Stevens AB et al (2007). Effects of chronic stress and interleukin-10 gene polymorphisms on antibody response to tetanus vaccine in family caregivers of patients with Alzheimer's disease. Psychosom Med 69: 551-559.

Lieb J, Karmali R, Horrobin D (1983). Elevated levels of prostaglandin E2 and thromboxane B2 in depression. Prostaglandins Leukot Med 10: 361-367.

Liu TF, Brown CM, El Gazzar M, McPhail L, Millet P, Rao A et al (2012a). Fueling the flame: bioenergy couples metabolism and inflammation. J Leukoc Biol 92: 499-507.

Liu Y, Ho RC, Mak A (2012b). Interleukin (IL)-6, tumour necrosis factor alpha (TNF-alpha) and soluble interleukin-2 receptors (SIL-2 R) are elevated in patients with major depressive disorder: a meta-analysis and meta-regression. J Affect Disord 139: 230-239.

Lo Sasso G, Ryu D, Mouchiroud L, Fernando SC, Anderson CL, Katsyuba E et al (2014). Loss of Sirt1 function improves intestinal anti-bacterial defense and protects from colitis-induced colorectal cancer. PLOS ONE 9: e102495.

Lotrich FE (2009). Major depression during interferon-alpha treatment: vulnerability and prevention. Dialogues Clin Neurosci 11: 417-425.

Lotrich FE, Ferrell RE, Rabinovitz M, Pollock BG (2009). Risk for depression during interferon-alpha treatment is affected by the serotonin transporter polymorphism. Biol Psychiatry 65: 344-348.

Macy EM, Hayes TE, Tracy RP (1997). Variability in the measurement of C-reactive protein in healthy subjects: implications for reference intervals and epidemiological applications. Clin Chem 43: 52-58.

Maes M (1999). Major depression and activation of the inflammatory response system. Adv Exp Med Biol 461: 25-46.

Maes M, Meltzer HY, Bosmans E, Bergmans R, Vandoolaeghe E, Ranjan R et al (1995). Increased plasma concentrations of interleukin-6, soluble interleukin-6, soluble interleukin-2 and transferrin receptor in major depression. $J$ Affect Disord 34: 301-309. 
Maes M, Meltzer HY, Scharpe S, Cooreman W, Uyttenbroeck W, Suy E et al (1993). Psychomotor retardation, anorexia, weight loss, sleep disturbances, and loss of energy: psychopathological correlates of hyperhaptoglobinemia during major depression. Psychiatry Res 47: 229-241.

Majer M, Wellberg LAM, Capuron L, Pagnoni G, Raison CL, Miller AH (2008). IFN-alpha-induced motor slowing is associated with increased depression and fatigue in patients with chronic hepatitis C. Brain. Behav Immun 25: 870-880.

Matza LS, Revicki DA, Davidson JR, Stewart JW (2003). Depression with atypical features in the National Comorbidity Survey: classification, description, and consequences. Arch Gen Psychiatry 60: 817-826.

May L, van den Biggelaar AH, van Bodegom D, Meij HJ, de Craen AJ, Amankwa J et al (2009). Adverse environmental conditions influence age-related innate immune responsiveness. Immun Ageing 6: 7 .

Mays JW, Bailey MT, Hunzeker JT, Powell ND, Papenfuss T, Karlsson EA et al (2010). Influenza virus-specific immunological memory is enhanced by repeated social defeat. J Immunol 184: 2014-2025.

Mays JW, Powell ND, Hunzeker JT, Hanke ML, Bailey MT, Sheridan JF (2012). Stress and the anti-influenza immune response: repeated social defeat augments clonal expansion of $\mathrm{CD} 8(+) \mathrm{T}$ cells during primary influenza $\mathrm{A}$ viral infection. J Neuroimmunol 243: 34-42.

McCullers JA, McAuley JL, Browall S, Iverson AR, Boyd KL, Henriques Normark B (2010). Influenza enhances susceptibility to natural acquisition of and disease due to Streptococcus pneumoniae in ferrets. J Infect Dis 202: 1287-1295.

McDade TW, Georgiev AV, Kuzawa CW (2016). Trade-offs between acquired and innate immune defenses in humans. Evol Med Public Health 2016: 1-16.

McDade TW, Hoke M, Borja JB, Adair LS, Kuzawa C (2012a). Do environments in infancy moderate the association between stress and inflammation in adulthood? Initial evidence from a birth cohort in the Philippines. Brain Behav Immun 31: 23-30.

McDade TW, Rutherford JN, Adair L, Kuzawa C (2009). Population differences in associations between C-reactive protein concentration and adiposity: comparison of young adults in the Philippines and the United States. Am J Clin Nutr 89: 1237-1245.

McDade TW, Tallman PS, Madimenos FC, Liebert MA, Cepon TJ, Sugiyama LS et al (2012b). Analysis of variability of high sensitivity C-reactive protein in lowland Ecuador reveals no evidence of chronic low-grade inflammation. Am J Hum Biol 24: 675-681

Mendez FL, Watkins JC, Hammer MF (2012). A haplotype at STAT2 Introgressed from neanderthals and serves as a candidate of positive selection in Papua New Guinea. Am J Hum Genet 91: 265-274.

Michan S, Sinclair D (2007). Sirtuins in mammals: insights into their biological function. Biochem J 404: 1-13.

Milanski M, Degasperi G, Coope A, Morari J, Denis R, Cintra DE et al (2009). Saturated fatty acids produce an inflammatory response predominantly through the activation of TLR4 signaling in hypothalamus: implications for the pathogenesis of obesity. J Neurosci 29: 359-370.

Miller AH, Raison CL (2015). The role of inflammation in depression: from evolutionary imperative to modern treatment target. Nat Rev Immunol 16: 22-34.

Miller GE, Cohen S (2005). Infectious disease and psychoneuroimmunology. In: Hum Psychoneuroimmunol. Vedhara K, Irwin MR eds. Oxford University Press: Oxford, UK.

Mitra AK, Clarke K (2010). Viral obesity: fact or fiction? Obes Rev 11: 289-296.

Moieni M, Irwin MR, Jevtic I, Breen EC, Cho HJ, Arevalo JM et al (2015a). Trait sensitivity to social disconnection enhances pro-inflammatory responses to a randomized controlled trial of endotoxin. Psychoneuroendocrinology 62: 336-342.

Moieni M, Irwin MR, Jevtic I, Olmstead R, Breen EC, Eisenberger NI (2015b). Sex differences in depressive and socioemotional responses to an inflammatory challenge: implications for sex differences in depression. Neuropsychopharmacology 40: 1709-1716.

Molyneux EM, Tembo M, Kayira K, Bwanaisa L, Mweneychanya J, Njobvu A et al (2003). The effect of HIV infection on paediatric bacterial meningitis in Blantyre, Malawi. Arch Dis Child 88: 1112-1118.

Moraska A, Campisi J, Nguyen KT, Maier SF, Watkins LR, Fleshner M (2002). Elevated IL-1beta contributes to antibody suppression produced by stress. J Appl Physiol 93: 207-215.

Moieni M, Irwin MR, Jevtic I, Olmstead R, Breen EC, Eisenberger NI (2015). Sex differences in depressive and socioemotional responses to an inflammatory challenge: implications for sex differences in depression. Neuropsychopharmacol 40: 1709-1716.

Moussavi S, Chatterii S, Verdes E, Tandon A, Patel V, Ustun B (2007). Depression, chronic diseases, and decrements in health: results from the World Health Surveys. Lancet 370: 851-858.
Muller AJ, Sharma MD, Chandler PR, Duhadaway JB, Everhart ME, Johnson BA 3rd et al (2008). Chronic inflammation that facilitates tumor progression creates local immune suppression by inducing indoleamine 2,3 dioxygenase. Proc Natl Acad Sci USA 105: 17073-17078.

Musselman DL (2001). Higher than normal plasma interleukin-6 concentrations in cancer patients with depression: preliminary findings. Am J Psychiatry 158: 1252-1257.

Nguyen KB, Biron CA (1999). Synergism for cytokine-mediated disease during concurrent endotoxin and viral challenges: roles for NK and T cell IFN-gamma production. J Immunol 162: 5238-5246.

Nillni YI, Wesselink AK, Gradus JL, Hatch EE, Rothman KJ, Mikkelsen EM et al (2016). Depression, anxiety, and psychotropic medication use and fecundability. Am J Obstet Gynecol ; e-pub ahead of print 27 April 2016; doi: 10.1016/j. ajog.2016.04.022.

Ockene IS, Matthews CE, Rifai N, Ridker PM, Reed G, Stanek E (2001). Variability and classification accuracy of serial high-sensitivity C-reactive protein measurements in healthy adults. Clin Chem 47: 444-450.

Oddy WH, Rosales F (2010). A systematic review of the importance of milk TGF-beta on immunological outcomes in the infant and young child. Pediatr Allergy Immunol 21: 47-59.

Ogawa J, Sasahara A, Yoshida T, Sira MM, Futatani T, Kanegane H et al (2004). Role of transforming growth factor-beta in breast milk for initiation of IgA production in newborn infants. Early Hum Dev 77: 67-75.

Opp MR (2004). Cytokines and sleep: the first hundred years. Brain Behav Immun 18: 295-297.

Opp MR (2009). Sleeping to fuel the immune system: mammalian sleep and resistance to parasites. BMC Evol Biol 9: 8

Owczarczyk AB, Schaller MA, Reed M, Rasky AJ, Lombard DB, Lukacs NW (2015). Sirtuin 1 regulates dendritic cell activation and autophagy during respiratory syncytial virus-induced immune responses. J Immunol 195: 1637-1646.

Pace TW, Mletzko TC, Alagbe O, Musselman DL, Nemeroff CB, Miller AH et al (2006a). Increased stress-induced inflammatory responses in male patients with major depression and increased early life stress. Am J Psychiatry 163: 1630-1633.

Pace TW, Mletzko TC, Alagbe O, Musselman DL, Nemeroff CB, Miller AH et al (2006b). Increased stress-induced inflammatory responses in male patients with major depression and increased early life stress. Am J Psychiatry 163 1630-1633.

Pacheco AG, Cardoso CC, Moraes MO (2008). IFNG +874 T/A, IL10 -1082G/A and TNF -308G/A polymorphisms in association with tuberculosis susceptibility: a meta-analysis study. Hum Genet 123: 477-484.

Park SY, Lee SW, Kim HY, Lee SY, Lee WS, Hong KW et al (2016). SIRT1 inhibits differentiation of monocytes to macrophages: amelioration of synovial inflammation in rheumatoid arthritis. J Mol Med (Berl) 94: 921-931.

Pasco JA, Jacka FN, Williams LJ, Henry MJ, Nicholson GC, Kotowicz MA et al (2008). Leptin in depressed women: cross-sectional and longitudinal data from an epidemiologic study. J Affect Disord 107: 221-225.

Patel SR, Zhu X, Storfer-Isser A, Mehra R, Jenny NS, Tracy R et al (2009). Sleep duration and biomarkers of inflammation. Sleep 32: 200-204.

Patten SB, Wang JL, Williams JV, Currie S, Beck CA, Maxwell CJ et al (2006). Descriptive epidemiology of major depression in Canada. Can J Psychiatry 51 84-90.

Pednekar MS, Hakama M, Hebert JR, Gupta PC (2008). Association of body mass index with all-cause and cause-specific mortality: findings from a prospective cohort study in Mumbai (Bombay), India. Int J Epidemio/ 37: 524-535.

Perrier E, Pompei F, Ruberto G, Vassos E, Collier D, Frangou S (2011). Initial evidence for the role of CACNA1C on subcortical brain morphology in patients with bipolar disorder. Eur Psychiatry 26: 135-137.

Pinker S. The better angels of our nature: why violence has declined. Viking Books: New York, NY, 2011.

Pinto RA, Arredondo SM, Bono MR, Gaggero AA, Diaz PV (2006). T helper 1/T helper 2 cytokine imbalance in respiratory syncytial virus infection is associated with increased endogenous plasma cortisol. Pediatrics 117: e878-e886.

Poltorak M, Frye MA, Wright R, Hemperly JJ, George MS, Pazzaglia PJ et al (1996). Increased neural cell adhesion molecule in the CSF of patients with mood disorder. J Neurochem 66: 1532-1538.

Posey KA, Clegg DJ, Printz RL, Byun J, Morton GJ, Vivekanandan-Giri A et al (2009). Hypothalamic proinflammatory lipid accumulation, inflammation, and insulin resistance in rats fed a high-fat diet. Am J Physiol Endocrinol Metab 296: E1003-E1012.

Posternak MA, Zimmerman M (2001). Symptoms of atypical depression. Psychiatry Res 104: 175-181.

Powell ND, Mays JW, Bailey MT, Hanke ML, Sheridan JF (2010). Immunogenic dendritic cells primed by social defeat enhance adaptive immunity to influenza A virus. Brain Behav Immun. 25: 46-52. 
Prather AA, Rabinovitz M, Pollock BG, Lotrich FE (2009). Cytokine-induced depression during IFN-alpha treatment: The role of IL-6 and sleep quality. Brain Behav Immun. 23: 1109-1116.

Prather AA, Vogelzangs N, Penninx BW (2015). Sleep duration, insomnia, and markers of systemic inflammation: results from the Netherlands Study of Depression and Anxiety (NESDA). J Psychiatr Res 60: 95-102.

Pravica V, Asderakis A, Perrey C, Hajeer A, Sinnott PJ, Hutchinson IV (1999). In vitro production of IFN-gamma correlates with CA repeat polymorphism in the human IFN-gamma gene. Eur J Immunogenet 26: 1-3.

Pravica V, Perrey C, Stevens A, Lee JH, Hutchinson IV (2000). A single nucleotide polymorphism in the first intron of the human IFN-gamma gene: absolute correlation with a polymorphic CA microsatellite marker of high IFN-gamma production. Hum Immunol 61: 863-866.

Quan N, Avitsur R, Stark JL, He L, Shah M, Caligiuri M et al (2001). Social stress increases the susceptibility to endotoxic shock. J Neuroimmunol 115: 36-45.

Raison CL, Borisov AS, Majer M, Drake DF, Pagnoni G, Woolwine BJ et al (2009). Activation of central nervous system inflammatory pathways by interferon-alpha: relationship to monoamines and depression. Biol Psychiatry 65: 296-303.

Raison CL, Borisov AS, Woolwine BJ, Massung B, Vogt G, Miller AH (2010a). Interferon-alpha effects on diurnal hypothalamic-pituitary-adrenal axis activity: relationship with proinflammatory cytokines and behavior. Mol Psychiatry 15: 535-547.

Raison CL, Broadwell SD, Borisov AS, Manatunga AK, Woolwine BJ, Jacobson IM et al (2005). Depressive symptoms and viral clearance in patients receiving interferon-alpha and ribavirin for hepatitis C. Brain. Behav Immun 19: 23-27.

Raison CL, Dantzer R, Kelley KW, Lawson MA, Woolwine BJ, Vogt G et al (2010b). CSF concentrations of brain tryptophan and kynurenines during immune stimulation with IFN-alpha: relationship to CNS immune responses and depression. Mol Psychiatry 15: 393-403.

Raison CL, Lowry CA, Rook GA (2010c). Inflammation, sanitation, and consternation: loss of contact with coevolved, tolerogenic microorganisms and the pathophysiology and treatment of major depression. Arch Gen Psychiatry 67: 1211-1224.

Raison CL, Miller AH (2012). The evolutionary significance of depression in Pathogen Host Defense (PATHOS-D). Mol Psychiatry. 18: 15-37.

Raison CL, Miller AH (2013). Malaise, melancholia and madness: the evolutionary legacy of an inflammatory bias. Brain Behav Immun 31: 1-8.

Raison CL, Rye DB, Woolwine BJ, Vogt GJ, Bautista BM, Spivey JR et al (2010d). Chronic interferon-alpha administration disrupts sleep continuity and depth in patients with hepatitis C: association with fatigue, motor slowing, and increased evening cortisol. Biol Psychiatry 68: 942-949.

Ratcliffe M (2013). A bad case of the flu? The comparative phenomenology of depression and somatic illness. Journal of Consciousness Studies 21: 198-218.

Ren JH, Tao Y, Zhang ZZ, Chen WX, Cai XF, Chen K et al (2014). Sirtuin 1 regulates hepatitis B virus transcription and replication by targeting transcription factor AP-1. J Virol 88: 2442-2451.

Rosenberger PH, Ickovics JR, Epel E, Nadler E, Jokl P, Fulkerson JP et al (2009). Surgical stress-induced immune cell redistribution profiles predict short-term and long-term postsurgical recovery. A prospective study. J Bone Joint Surg Am 91: 2783-2794.

Ross SR, Bloomsmith MA, Bettinger TL, Wagner KE (2009). The influence of captive adolescent male chimpanzees on wounding: management and welfare implications. Zoo Biol 28: 623-634.

Roth $J$ (2009). Evolutionary speculation about tuberculosis and the metabolic and inflammatory processes of obesity. JAMA 301: 2586-2588.

Rovira-Vallbona E, Moncunill G, Bassat Q, Aguilar R, Machevo S, Puyol L et al (2012). Low antibodies against Plasmodium falciparum and imbalanced proinflammatory cytokines are associated with severe malaria in Mozambican children: a case-control study. Malar J 11: 181.

Rubin RT, Rhodes ME, Czambel RK (2002). Sexual diergism of baseline plasma leptin and leptin suppression by arginine vasopressin in major depressives and matched controls. Psychiatry Res 113: 255-268.

Schaller M (2011). The behavioural immune system and the psychology of human sociality. Philos Trans R Soc Lond B Biol Sci 366: 3418-3426.

Schaller M, Miller GE, Gervais WM, Yager S, Chen E (2010). Mere visual perception of other people's disease symptoms facilitates a more aggressive immune response. Psychol Sci 21: 649-652.

Schaller M, Murray DR (2008). Pathogens, personality, and culture: disease prevalence predicts worldwide variability in sociosexuality, extraversion, and openness to experience. J Pers Soc Psychol 95: 212-221.

Schmider J, Lammers CH, Gotthardt U, Dettling M, Holsboer F, Heuser IJ (1995). Combined dexamethasone/corticotropin-releasing hormone test in acute and remitted manic patients, in acute depression, and in normal controls: I. Biol Psychiat 38: 797-802.
Sear R, Mace R (2008). Who keeps children alive? A review of the effects of kin on child survival. Evol Hum Behav 29: 1-18.

Seedat S, Scott KM, Angermeyer MC, Berglund P, Bromet EJ, Brugha TS et al (2009). Cross-national associations between gender and mental disorders in the World Health Organization World Mental Health Surveys. Arch Gen Psychiatry 66: 785-795

Segurel L, Quintana-Murci L (2014). Preserving immune diversity through ancient inheritance and admixture. Curr Opin Immunol 30: 79-84.

Shelton RC, Claiborne J, Sidoryk-Wegrzynowicz M, Reddy R, Aschner M, Lewis DA et al (2010). Altered expression of genes involved in inflammation and apoptosis in frontal cortex in major depression. Mol Psychiatry. 16: 751-762.

Simonti CN, Vernot B, Bastarache L, Bottinger E, Carrell DS, Chisholm RL et al (2016). The phenotypic legacy of admixture between modern humans and Neandertals. Science 351: 737-741.

Singh A, Smoak BL, Patterson KY, LeMay LG, Veillon C, Deuster PA (1991). Biochemical indices of selected trace minerals in men: effect of stress. Am J Clin Nutr 53: 126-131.

Slavich GM, Cole SW (2013). The emerging field of human social genomics. Clin Psychol Sci 1: 331-348.

Slavich GM, Way BM, Eisenberger NI, Taylor SE (2010). Neural sensitivity to social rejection is associated with inflammatory responses to social stress. Proc Natl Acad Sci USA 107: 14817-14822.

Sluzewska A, Rybakowski J, Bosmans E, Sobieska M, Berghmans R, Maes M et al (1996). Indicators of immune activation in major depression. Psychiatry Res 64: 161-167.

Smith DJ, Kyle S, Forty L, Cooper C, Walters J, Russell E et al (2008). Differences in depressive symptom profile between males and females. J Affect Disord 108: 279-284.

Song C, Lin A, Bonaccorso S, Heide C, Verkerk R, Kenis G et al (1998). The inflammatory response system and the availability of plasma tryptophan in patients with primary sleep disorders and major depression. J Affect Disord 49: 211-219.

Soszynski D, Kozak W, Conn CA, Rudolph K, Kluger MJ (1996). Beta-adrenoceptor antagonists suppress elevation in body temperature and increase in plasma IL-6 in rats exposed to open field. Neuroendocrinology 63: 459-467.

Spoor JR, Williams KD (2011). The evolution of an ostracism detection system. In: Evolution and the Social Mind: Evolutionary Psychology and Social Cognition, Forgas JP et al eds. pp 279-292, Psychology Press: Abingdon, UK.

Stein A, Gath DH, Bucher J, Bond A, Day A, Cooper PJ (1991). The relationship between post-natal depression and mother-child interaction. Br J Psychiatry 158: 46-52.

Steptoe A, Hamer M, Chida Y (2007). The effect of acute psychological stress on circulating inflammatory factors in humans: a review and meta-analysis. Brain Behav Immun 7: 901-912.

Stieglitz J, Schniter E, von Rueden C, Kaplan H, Gurven M (2015a). Functional disability and social conflict increase risk of depression in older adulthood among bolivian forager-farmers. J Gerontol B Psychol Sci Soc Sci 70: 948-956.

Stieglitz J, Trumble BC, Thompson ME, Blackwell AD, Kaplan H, Gurven M (2015b). Depression as sickness behavior? A test of the host defense hypothesis in a high pathogen population. Brain Behav Immun 49: 130-139.

Tang HM, Gao WW, Chan CP, Cheng Y, Deng JJ, Yuen KS et al (2015). SIRT1 suppresses human T-cell leukemia virus type 1 transcription. J Virol 89: 8623-8631.

Tarr AJ, Chen Q, Wang Y, Sheridan JF, Quan N (2012a). Neural and behavioral responses to low-grade inflammation. Behav Brain Res 235: 334-341.

Tarr AJ, Powell ND, Reader BF, Bhave NS, Roloson AL, Carson WE 3rd et al (2012b). beta-Adrenergic receptor mediated increases in activation and function of natural killer cells following repeated social disruption. Brain Behav Immun 26: 1226-1238.

Thase ME (2009). Atypical depression: useful concept, but it's time to revise the DSM-IV criteria. Neuropsychopharmacology 34: 2633-2641.

Thornhill R, Fincher CL, Aran D (2009). Parasites, democratization, and the liberalization of values across contemporary countries. Biol Rev Camb Philos Soc 84: 113-131

Torres OA, Calzada JE, Beraun Y, Morillo CA, Gonzalez A, Gonzalez Cl et al (2010). Role of the IFNG +874 T/A polymorphism in Chagas disease in a Colombian population. Infect Genet Evol 10: 682-685.

Trivers RL (1972). Parental investment and sexual selection. In: Sexual Selection and the Descent of Man. Campbell B. ed. pp 136-179, Heinemann: London.

Udina M, Castellvi P, Moreno-Espana J, Navines R, Valdes M, Forns X et al (2012). Interferon-induced depression in chronic hepatitis C: a systematic review and meta-analysis. J Clin Psychiatry 73: 1128-1138.

Vachharajani VT, Liu T, Wang X, Hoth JJ, Yoza BK, McCall CE (2016). Sirtuins link inflammation and metabolism. J Immunol Res 2016: 8167273. 
Vaknin I, Blinder L, Wang L, Gazit R, Shapira E, Genina O et al (2008). A common pathway mediated through Toll-like receptors leads to $\mathrm{T}$ - and natural killer-cell immunosuppression. Blood 111: 1437-1447.

Valkanova V, Ebmeier KP, Allan CL (2013). CRP, IL-6 and depression: a systematic review and meta-analysis of longitudinal studies. J Affect Disord 150: 736-744.

Van Bodegom D, May L, Meij HJ, Westendorp RG (2007). Regulation of human life histories: the role of the inflammatory host response. Ann N Y Acad Sci 1100: 84-97.

van Crevel R, Karyadi E, Netea MG, Verhoef H, Nelwan RH, West CE et al (2002). Decreased plasma leptin concentrations in tuberculosis patients are associated with wasting and inflammation. J Clin Endocrinol Metab 87: 758-763.

van Dissel JT, van Langevelde P, Westendorp RG, Kwappenberg K, Frolich M (1998). Anti-inflammatory cytokine profile and mortality in febrile patients. Lancet 351: 950-953.

van Dooren FE, Schram MT, Schalkwijk CG, Stehouwer CD, Henry RM, Dagnelie PC et al (2016). Associations of low grade inflammation and endothelial dysfunction with depression-The Maastricht Study. Brain Behav Immun. 56: 390-396.

Vernot B, Tucci S, Kelso J, Schraiber JG, Wolf AB, Gittelman RM et al (2016). Excavating Neandertal and Denisovan DNA from the genomes of Melanesian individuals. Science 352: 235-239.

Viswanathan K, Daugherty C, Dhabhar FS (2005). Stress as an endogenous adjuvant: augmentation of the immunization phase of cell-mediated immunity. Int Immunol 17: 1059-1069.

Vogelzangs N, Beekman AT, de Jonge P, Penninx BW (2013). Anxiety disorders and inflammation in a large adult cohort. Transl Psychiatry 3: e249.

Westendorp RG, Langermans JA, Huizinga TW, Elouali AH, Verweij CL, Boomsma DI et al (1997). Genetic influence on cytokine production and fatal meningococcal disease. Lancet 349: 170-173.

Wichers MC, Kenis G, Koek GH, Robaeys G, Nicolson NA, Maes M (2007). Interferon-alpha-induced depressive symptoms are related to changes in the cytokine network but not to cortisol. J Psychosom Res 62: 207-214.

Wichers MC, Kenis G, Leue C, Koek G, Robaeys G, Maes M (2006). Baseline immune activation as a risk factor for the onset of depression during interferonalpha treatment. Biol Psychiatry 60: 77-79.

Wichers MC, Koek GH, Robaeys G, Praamstra AJ, Maes M (2005a). Early increase in vegetative symptoms predicts IFN-alpha-induced cognitive-depressive changes. Psychol Med 35: 433-441.
Wichers MC, Koek GH, Robaeys G, Praamstra AJ, Maes M (2005b). Early increase in vegetative symptoms predicts IFN-alpha-induced cognitive-depressive changes. Psychol Med 35: 433-441.

Wichers MC, Maes M (2004). The role of indoleamine 2,3-dioxygenase (IDO) in the pathophysiology of interferon-alpha-induced depression. J Psychiatry Neurosci 29: 11-17.

Wieland CW, Florquin S, Chan ED, Leemans JC, Weijer S, Verbon A et al (2005). Pulmonary Mycobacterium tuberculosis infection in leptin-deficient ob/ob mice. Int Immunol 17: 1399-1408.

Williams KE, Marsh WK, Rasgon NL (2007). Mood disorders and fertility in women: a critical review of the literature and implications for future research. Hum Reprod Update 13: 607-616.

Wright CE, Strike PC, Brydon L, Steptoe A (2005). Acute inflammation and negative mood: mediation by cytokine activation. Brain Behav Immun 19: 345-350.

Yang K, Xie G, Zhang Z, Wang C, Li W, Zhou W et al (2007). Levels of serum interleukin (IL)-6, IL-1beta, tumour necrosis factor-alpha and leptin and their correlation in depression. Aust N Z J Psychiatry 41: 266-273.

Yang YW, Tseng KC, Chen YH, Yang JY (2010). Associations among eczema, asthma, serum immunoglobulin $\mathrm{E}$ and depression in adults: a populationbased study. Allergy 65: 801-802.

Zeman M, Jirak R, Jachymova M, Vecka M, Tvrzicka E, Zak A (2009). Leptin, adiponectin, leptin to adiponectin ratio and insulin resistance in depressive women. Neuro Endocrinol Lett 30: 387-395.

Zhang R, Chen HZ, Liu JJ, Jia YY, Zhang ZQ, Yang RF et al (2010a). SIRT1 suppresses activator protein-1 transcriptional activity and cyclooxygenase-2 expression in macrophages. J Biol Chem 285: 7097-7110.

Zhang X, Zhang G, Zhang H, Karin M, Bai H, Cai D (2008). Hypothalamic IKKbeta/ NF-kappaB and ER stress link overnutrition to energy imbalance and obesity. Cell 135: 61-73.

Zhang Z, Lowry SF, Guarente L, Haimovich B (2010b). Roles of SIRT1 in the acute and restorative phases following induction of inflammation. J Biol Chem 285: 41391-41401.

Zhao M, Chen J, Wang W, Wang L, Ma L, Shen H et al (2008). Psychological stress induces hypoferremia through the IL-6-hepcidin axis in rats. Biochem Biophys Res Commun 373: 90-93.

Zorrilla EP, McKay JR, Luborsky L, Schmidt K (1996). Relation of stressors and depressive symptoms to clinical progression of viral illness. Am J Psychiatry 153: 626-635.

Supplementary Information accompanies the paper on the Neuropsychopharmacology Reviews website (http://www.nature. com/npp) 